\title{
Utilization of biomass: Conversion of model compounds to hydrocarbons over zeolite
} H-ZSM-5

\section{Mentzel, Uffe Vie; Holm, Martin Spangsberg}

Published in:

Applied Catalysis A: General

Link to article, DOI:

10.1016/j.apcata.2011.01.040

Publication date:

2011

Link back to DTU Orbit

Citation (APA):

Mentzel, U. V., \& Holm, M. S. (2011). Utilization of biomass: Conversion of model compounds to hydrocarbons over zeolite H-ZSM-5. Applied Catalysis A: General, 396(1-2), 59-67.

https://doi.org/10.1016/j.apcata.2011.01.040

\section{General rights}

Copyright and moral rights for the publications made accessible in the public portal are retained by the authors and/or other copyright owners and it is a condition of accessing publications that users recognise and abide by the legal requirements associated with these rights.

- Users may download and print one copy of any publication from the public portal for the purpose of private study or research.

- You may not further distribute the material or use it for any profit-making activity or commercial gain

- You may freely distribute the URL identifying the publication in the public portal

If you believe that this document breaches copyright please contact us providing details, and we will remove access to the work immediately and investigate your claim 


\section{Accepted Manuscript}

Title: Utilization of Biomass: Conversion of Model

Compounds to Hydrocarbons over Zeolite H-ZSM-5

Authors: Uffe V. Mentzel, Martin S. Holm

PII: $\quad$ S0926-860X(11)00056-1

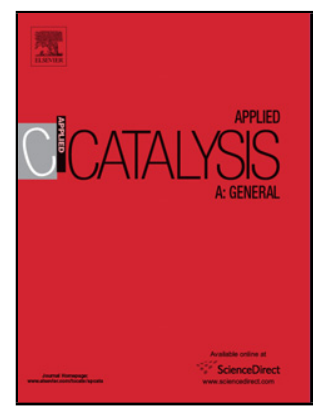

DOI:

doi:10.1016/j.apcata.2011.01.040

Reference:

APCATA 13016

To appear in:

Applied Catalysis A: General

Received date:

23-11-2010

Revised date:

25-1-2011

Accepted date:

27-1-2011

Please cite this article as: U.V. Mentzel, M.S. Holm, Utilization of Biomass: Conversion of Model Compounds to Hydrocarbons over Zeolite H-ZSM-5, Applied Catalysis A, General (2010), doi:10.1016/j.apcata.2011.01.040

This is a PDF file of an unedited manuscript that has been accepted for publication. As a service to our customers we are providing this early version of the manuscript. The manuscript will undergo copyediting, typesetting, and review of the resulting proof before it is published in its final form. Please note that during the production process errors may be discovered which could affect the content, and all legal disclaimers that apply to the journal pertain. 


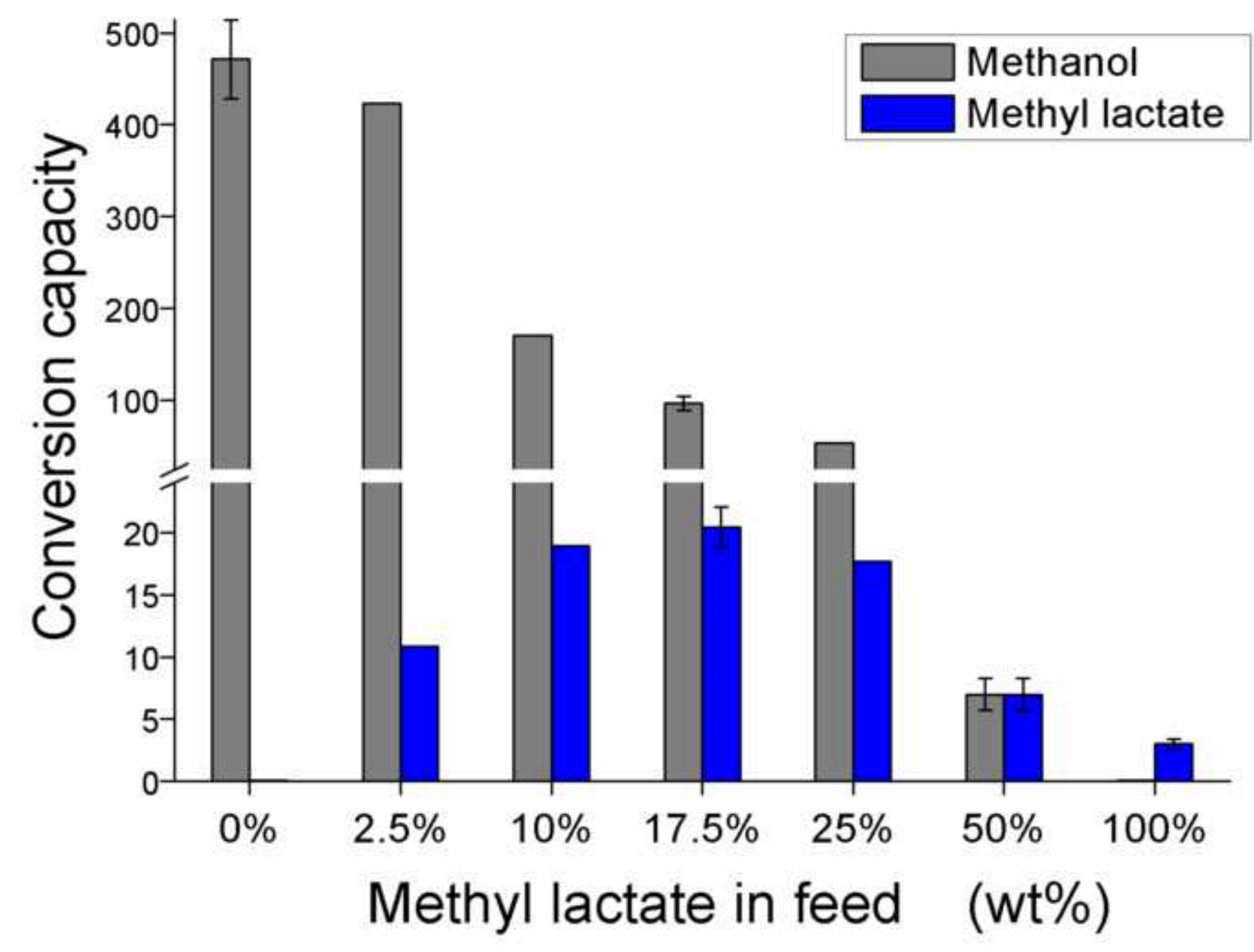


- Different conversion capacities are seen when co-feeding structural isomers in $\mathrm{MTH}$

- Methanol dilution increases conversion capacity of the additive by up to 10 times

- Acids and esters favor deoxygenation through $\mathrm{CO} / \mathrm{CO}_{2}$ dissociation over dehydration

- ${ }^{13} \mathrm{C}$ labeling indicates that additives are incorporated via the aromatic products 


\title{
Utilization of Biomass:
}

\section{Conversion of Model Compounds to Hydrocarbons over Zeolite H-ZSM-5}

\author{
Uffe V. Mentzel*,a,b and Martin S. Holm*,a,b \\ ${ }^{a}$ Centre for Catalysis and Sustainable Chemistry, Department of Chemistry, Technical University of \\ Denmark, Anker Engelundsvej 1, 2800 Kgs. Lyngby, Denmark, DK. \\ ${ }^{\mathrm{b}}$ Center for Green and Sustainable Chemistry, Department of Chemistry, Technical University of \\ Denmark, Anker Engelundsvej 1, 2800 Kgs. Lyngby, Denmark, DK. \\ uvm@kemi.dtu.dk,msh@kemi.dtu.dk \\ *Corresponding author
}

\begin{abstract}
Zeolite catalyzed deoxygenation of small oxygenates present in bio-oil or selected as model compounds was performed under Methanol-to-Hydrocarbons (MTH) like reaction conditions using H-ZSM-5 as the catalyst. Co-feeding of the oxygenates with methanol generally decreases catalyst lifetime due to coking and results in higher selectivity towards aromatics compared to conversion of pure methanol. The reaction pattern of the different oxygenates did not simply follow the effective $\mathrm{H} / \mathrm{C}$ ratio of the additives since structural isomers with identical effective $\mathrm{H} / \mathrm{C}$ ratios showed significant differences with respect to catalyst lifetime and product selectivity. A distinct positive effect on catalyst lifetime was observed for methanol dilution. Thus, the conversion capacity of the catalyst was up to 10 times higher when the reactant was diluted in methanol. We observe that in particular acid/ester functionalities favor oxygen removal through decarbonylation over dehydration which preserves hydrogen in the hydrocarbon product mixture. By employing ${ }^{13} \mathrm{C}$ labeled substrates we confirmed the incorporation of carbon into the hydrocarbon products as well as a pronounced preference of the additive carbon towards incorporation into aromatic compounds.
\end{abstract}

\section{KEYWORDS}

Zeolite, ZSM-5, Methanol-to-Hydrocarbons (MTH), Bio-oil, Biomass-to-liquids (BTL)

\section{Introduction}

The development of a more sustainable and environmentally friendly production of chemicals and transportation fuels is pursued today [1]. The use of a biomass derived fuel additives such as bioethanol or bio-diesel represent examples of current strategies towards the employment of "greener" fuels $[2,3]$.

Bio-oil can be produced from numerous types of biomass through a rapid thermal treatment with no or only little oxygen present. Bio-oil represents an abundant and near $\mathrm{CO}_{2}$ neutral resource which could find application if sufficiently efficient upgrading strategies are identified. Depending on the 
starting material and the specific treatment conditions, large compositional discrepancies are seen within bio-oils but in general it is a highly complex mixture of oxygenates produced by depolymerization and fragmentation of cellulose, hemi-cellulose, and lignin [4]. Bio-oil is immiscible with hydrocarbons, contains large amounts of water, and is relatively unstable, however the liquid has an advantage over untreated biomass with respect to handling and transportation $[5,6]$. Transformation of bio-oil into a mixture of hydrocarbons through zeolite catalyzed deoxygenation is highly desired and could ensure compatibility with conventional gasoline [7]. In fact, researchers at Mobil already in the years following the discovery of the Methanol-to-gasoline (MTG) process [8] investigated this idea of converting biomass into hydrocarbons primarily over zeolite ZSM-5 [9,10]. They introduced the effective $\mathrm{H} / \mathrm{C}$ ratio of a substrate (see Equation 1), with $\mathrm{H}, \mathrm{O}$, and $\mathrm{C}$ being the moles of hydrogen, oxygen, and carbon present in the compound. This is a convenient measure of the hydrogen content left in the products once oxygen is removed as water [11].

$$
\frac{\mathrm{H}}{\mathrm{C}} \text { effective }=\frac{(\mathrm{H}-20)}{\mathrm{C}}
$$

Equation 1: Definition of the effective $\mathrm{H} / \mathrm{C}$ ratio, where $\mathrm{H}, \mathrm{C}$, and $\mathrm{O}$ are the number of hydrogen, carbon, and oxygen atoms present in the specific compound.

Excessive deactivation of the catalyst by coking was discovered as a major problem when reacting compounds with an effective $\mathrm{H} / \mathrm{C}$ ratio below 2 . A carbohydrate with a molecular formula of $\mathrm{C}_{6} \mathrm{H}_{12} \mathrm{O}_{6}$ has an effective $\mathrm{H} / \mathrm{C}$ ratio of 0 and will thus be able to produce only carbon if fully dehydrated. However, if the reactants are deoxygenated by decarbonylation or decarboxylation (formation of $\mathrm{CO}$ or $\mathrm{CO}_{2}$, respectively) hydrogen is retained in the hydrocarbon products. Consequently, if a gasoline product mixture with a similar $\mathrm{H} / \mathrm{C}$ content as conventional MTH fuel is desired, a hexose would need to dissociate $1 / 3$ of its carbon atoms as $\mathrm{CO}_{2}$ which resembles fermentation where $\mathrm{CO}_{2}$ and ethanol are formed.

Several authors have reported on zeolite catalyzed conversion of bio-oil/pyrolysis vapors $[7,12,13,14,15,16,17]$ or selected model compounds present in bio-oil $[18,19,20,21,22,23,24,25,26,27,28,29,30,31]$ over mainly zeolite ZSM-5 at MTH-like reaction conditions. Due to the very complex nature of bio-oil only limited information regarding the reactivity of the individual components is obtained when feeding the highly complex bio-oil mixture which merits the investigation of representative model compounds. Very interestingly the reports show that hydrocarbons can indeed be produced from virtually any oxygenate but generally the catalyst suffers from extremely fast deactivation by coking. The addition of methanol, which has an effective $\mathrm{H} / \mathrm{C}$ ratio of 2 , will increase the combined $\mathrm{H} / \mathrm{C}$ ratio of the feed and has been reported to have a positive effect e.g. on the conversion of furfural [11,32]. Also dilution of bio-oil with methanol has been reported [33] and recently Bilbao and co-workers showed that methanol addition attenuates the condensation of pyrolytic lignin when the feed is heated prior to introduction to the reactor [34]. Significant improvements were thus achieved in a two-step process where the bio-oil and methanol mixture was volatilized in a separate unit before the catalytic conversion $[35,36]$.

The use of zeolite catalysts for conversion of biomass derived compounds in the high temperature range of FCC have also recently been reported [37,38,39]. In relation to this, Huber et al. used finely dispersed sugar physically blended with the catalyst while applying extremely rapid heating, and were thus able to produce single- and poly-aromatics alongside $\mathrm{CO}_{2}$ and water although also substantial coking of the catalyst occurs $[40,41,42]$. 
Here we present a study investigating the reactivity of selected oxygenates when co-fed with methanol at MTH reaction conditions over zeolite H-ZSM-5. The additives contain different functionalities and were selected to cover a wide range of $\mathrm{H} / \mathrm{C}$ ratios. The oxygenates were coreacted as $10 \mathrm{wt} \%$ solutions in methanol to obtain lifetimes between one hour and 2.5 days which made evaluation of their compatibility with MTH possible. The most interesting compounds were further tested in a $\mathrm{wt} \%$ series intended to quantify the positive effect of methanol dilution with respect to conversion capacity of the additive. Experiments using ${ }^{13} \mathrm{C}$-labeling of the substrates were performed in order to address whether the carbon atoms from the additives were in fact incorporated into the hydrocarbon products.

\section{Experimental}

The zeolite catalyst used in this study was a commercially available zeolite ZSM-5 with a Si/Al ratio of 40 kindly supplied by Zeolyst. The $\mathrm{NH}_{4}-\mathrm{ZSM}-5$ was transformed into proton form by calcination at $550{ }^{\circ} \mathrm{C}$ for 6 hours reached with a heating ramp of $2{ }^{\circ} \mathrm{C} / \mathrm{min}$.

Characterization by XRPD, $\mathrm{N}_{2}$-sorption, and elemental analysis of the commercial ZSM-5 sample is presented in supplementary data. Phase purity, crystallinity, and the nominal Si/Al ratio of 40 are confirmed.

Catalytic experiments were performed with $300 \mathrm{mg}$ of pure zeolite which was crushed and sieved to obtain particle size of $350-500 \mu \mathrm{m}$ and fixated by quartz wool in a quartz reactor having an internal diameter of $4 \mathrm{~mm}$. During heating to the reaction temperature $\left(370{ }^{\circ} \mathrm{C}\right)$ the catalyst was kept in a flow of helium of $40 \mathrm{ml} / \mathrm{min}$. The reactants were introduced by an HPLC pump at a rate of 0.05 $\mathrm{ml} / \mathrm{min}$ through a stainless steel tube (1/16 inch) heated to above the boiling point of the respective reactants. The constant feed volume gave a typical WHSV of around $8 \mathrm{~h}^{-1}$ depending on the density of the specific feed composition. Conversion capacities reported in $\mathrm{g}_{\text {feed }} / \mathrm{g}_{\text {zeolite }}$ for the individual experiments were calculated from the measured WHSV multiplied by the lifetime observed when a conversion of $50 \%$ of additive + methanol/DME was reached [44].

The reaction temperature was measured inside the reactor approximately $0.5 \mathrm{~cm}$ below the catalyst bed and was stabilized at $370{ }^{\circ} \mathrm{C}$ before the experiments. Steel piping $(1 / 4 \mathrm{inch})$ heated to $>200{ }^{\circ} \mathrm{C}$ directed the products to analysis by on-line GC equipped with an FID. Response factors of all hydrocarbons were assumed to be 1 while 0.63 and 0.81 was used for DME and methanol, respectively. Response factors for other oxygenates were estimated to be equal to that of DME. The concentrations of $\mathrm{CO}$ and $\mathrm{CO}_{2}$ in the effluent were determined by a BINOS instrument placed after condensation of liquids in a cold trap kept at $0{ }^{\circ} \mathrm{C}$.

In the case of experiments converting ${ }^{13} \mathrm{C}$ enriched reactants; the same setup, scaling and reaction conditions were used. The conversion and product selectivities were monitored by on-line GC in order to verify similarity with conventional runs while additional product samples were frequently withdrawn for GC-MS analyses. Calculation of the ${ }^{13} \mathrm{C}$ content in the products was done based on reference spectra obtained from reacting pure ${ }^{13} \mathrm{C}$ labeled methanol. In a typical ${ }^{13} \mathrm{C}$ experiment enough substrate was used to continue operation for approximately 1 hour. In all cases only minor deactivation occurs in this short time range thus giving information on additive carbon incorporation over a "fresh" catalyst. 
TPO (temperature programmed oxidation) of the deactivated catalysts was performed on $100 \mathrm{mg}$ of sample. The coked catalyst was heated from RT to $670{ }^{\circ} \mathrm{C}$ at a rate of $2.7^{\circ} \mathrm{C} / \mathrm{min}$ in a flow of 20 $\mathrm{ml} / \mathrm{min}$ of $5 \% \mathrm{O}_{2}$ in He. The formed $\mathrm{CO}$ and $\mathrm{CO}_{2}$ were continuously detected by a BINOS instrument.

All chemicals are commercially available and were used as purchased without further purification. A full list of chemical compounds is found in supplementary data.

\section{Results and Discussion}

\subsection{Additive screening}

An initial screening of pure compounds with relatively low effective $\mathrm{H} / \mathrm{C}$ ratios $(\leq 1.5)$ was done at MTH reaction conditions $\left(370^{\circ} \mathrm{C}\right)$ over $\mathrm{H}-\mathrm{ZSM}-5$. This resulted in catalyst lifetimes in the order of minutes which was in strong contrast to reacting methanol which gives a catalyst lifetime of around 65 hours. Clearly, this illustrated that excessive coking of the zeolite catalyst occurred when nonmono alcohols (ethylene glycol, propanediol, glycerol etc.) were converted. In order to examine all molecules under similar conditions we therefore chose to react the compounds diluted to $10 \mathrm{wt} \%$ in methanol. This resulted in catalyst lifetimes spanning from as little as $2 \%$ to approximately equal that of pure methanol thus illustrating the "toxicity" of co-converting the individual molecules. Table 1 presents the additives chosen for co-feeding, their effective $\mathrm{H} / \mathrm{C}$ ratio, the total conversion capacities in $\mathrm{g}_{\text {feed }} / \mathrm{g}_{\text {zeolite }}$ and the amounts of $\mathrm{CO}$ and $\mathrm{CO}_{2}$ formed (given as a percentage relative to the molar amount of additive introduced). The initial product distribution is described by grouped selectivities in combination with the $\mathrm{C}_{4}$-HTI (hydrogen transfer index) which is a descriptor of the hydrogen transfer activity of the catalyst (see equation 2) [43]. The $\mathrm{C}_{4}$-HTI and the selectivity were both measured approximately $5-10 \%$ into the full experiment run time. As is the case in conventional $\mathrm{MTH}$, the product selectivity in the co-feeding experiments shifts from large amounts of aromatic and paraffinic products towards olefins as the catalyst gradually deactivates [44].

$$
\mathrm{C}_{4} \text {-HTI }=\sum \frac{\text { Butanes }}{\text { Butanes }+ \text { Butenes }}
$$

Equation 2: Definition of the $\mathrm{C}_{4}$-HTI.

From the data in Table 1 we see that any additive leads to lower conversion capacities compared to conversion of pure methanol with the exception of water, formic acid and higher alcohols. The latter is in good correlation with results published recently [45] while water and formic acid (formic acid dissociates predominantly into CO and water) leads to a lower WHSV of methanol with an increased water concentration which presumably suppresses coke formation [29]. Co-feeding a $10 \mathrm{wt} \%$ solution of the phenolic species anisole or 1,2-dimethoxybenzene results in conversion capacities of $<10 \mathrm{~g}_{\text {feed }} / \mathrm{g}_{\text {zeolite. }}$ The huge difficulty in converting these species is in good agreement with previous reports where removal of phenolic species prior to bio-oil upgrading was suggested $[18,19]$. Other compounds which deactivate the catalyst strongly are levulinic acid, glycerol, and formaldehyde dimethyl acetal. These compounds all represent highly hydrogen deficient molecules with critically low effective $\mathrm{H} / \mathrm{C}$ ratios of $0.4,0.6$ and 1.33, respectively. As expected, compounds which are more compatible do indeed have higher effective $\mathrm{H} / \mathrm{C}$ ratios, e.g. 1,5-pentanediol. In general, lower conversion capacities are obtained for low $\mathrm{H} / \mathrm{C}$ ratios of the additives. Illustrative examples of this 
include hydroxy acetaldehyde (introduced as the dimethyl acetal) which deactivates the catalyst faster than acetaldehyde, glycerol is harder to convert than propanediol and butanoic acid performs better than the lower acids, however several additional features should be noted.

Figure 1 presents the conversion capacities from Table 1 plotted as a function of the effective $\mathrm{H} / \mathrm{C}$ ratio of the pure additive. Here it can be seen that compounds which have the same effective $\mathrm{H} / \mathrm{C}$ ratio do not give identical conversion capacities. This is observed for molecules containing oxygen in different functionalities as well as for positional isomers. A pronounced difference in the conversion capacity between 2,3-butanediol and the other butanediols is observed disregarding that they all have an effective $\mathrm{H} / \mathrm{C}$ ratio of 1.5 and contain the same functional groups. Interestingly butanone performs similar to 2,3-butanediol whereas butyraldehyde groups with the diols having one or two hydroxyl groups at a terminal carbon. This reactivity correlates with the detection of butanone as the direct dehydration product formed from 2,3-butanediol whereas predominantly butadiene and butyraldehyde are produced from 1,3- and 1,2-butanediol. However, tetrahydrofuran is the main dehydration product of 1,4-butanediol which gives a conversion capacity close to the latter isomers. The same tendency of higher conversion capacities of the ketone over the aldehyde is observed for acetone and propanal, where also 1,2-propanediol is significant better than the corresponding 1,3propanediol. However breakthrough of butanone and acetone before methanol/DME is observed which indicates a significantly lower reactivity as compared to the corresponding aldehydes. In all other cases the additive (or derivatives thereof) only starts to appear in the reactor outlet alongside unconverted methanol/DME.

Levulinic acid and $\gamma$-valerolactone can be derived from biomass [46,47] and represent along with 2methyl-tetrahydrofuran a series of molecules with an identical carbon backbone which are increasingly hydrogenated. From Figure 1 (and Table 1) we see that this series does indeed group according to their oxidation state, with the most reduced compounds performing superior, giving conversion capacities of around $10 \%, 20 \%$ and $55 \%$ compared to conversion of pure methanol, respectively. This observation can prove important since the use of 1 equivalent of $\mathrm{H}_{2}$ when going from levulinic acid to $\gamma$-valerolactone actually doubles the conversion capacity thus showing that partial hydrogenation could be advantageous.

In conventional MTH the alcohol oxygen is removed by dehydration. When converting higher oxidized compounds it would however be useful to remove oxygen by decarboxylation or decarbonylation in order to preserve hydrogen in the hydrocarbon products. Figure 1 shows that the acids and in particular methyl lactate performs significantly better than could be expected from their low $\mathrm{H} / \mathrm{C}$ ratios. Acetic acid forms only minor amounts of $\mathrm{CO}$ and $\mathrm{CO}_{2}(5 \%, 3 \%)$ while propanoic acid $(26 \%, 4 \%)$ and butyric acid $(62 \%, 0 \%)$ produce larger amounts of $\mathrm{CO}$. The high oxidation state of acetic acid in combination with a negligible tendency to dissociate $\mathrm{CO}$ and/or $\mathrm{CO}_{2}$ (at this concentration) leads to a very high initial aromatic carbon percentage of $35 \%$ compared to $29 \%$ for propanoic acid, $24 \%$ for butanoic acid and only $19 \%$ for pure methanol.

Figure 2 shows the initial carbon \% located in aromatic products plotted as a function of the effective $\mathrm{H} / \mathrm{C}$ ratio in the combined feed (methanol + additive) for the compounds in Table 1 . The coloring differentiates between molecules able to dissociate significant amounts $(>30 \%)$ of $\mathrm{CO}$ and/or $\mathrm{CO}_{2}$ (gray) and those unable (dark). Clearly, conversion of compounds deoxygenating through dehydration (dark) results in a relatively high selectivity towards aromatics while compounds which are able to split off $\mathrm{CO}$ or $\mathrm{CO}_{2}$ produce less aromatics. It appears that the intrinsic selectivity of the H-ZSM-5 zeolite forces the product distribution within the gasoline range and 
preserving hydrogen in the products increases the selectivity towards aliphatic products over the hydrogen deficient aromatic compounds.

Dissociation of $\mathrm{CO}$ is also relevant to explain the extraordinary good performance of methyl lactate. More than $90 \%$ of the introduced methyl lactate dissociate $\mathrm{CO}$ which is in good agreement with very recent results [48]. In fact after complete deactivation of the catalyst we observe a continued formation of mainly $\mathrm{CO}$, acetaldehyde and $\mathrm{DME} /$ methanol indicating that acetaldehyde and methanol are the "true" reactants when converting methyl lactate.

Also levulinic acid and $\gamma$-valerolactone form large amounts of $\mathrm{CO}$ and in the case of $\gamma$-valerolactone also small amounts of $\mathrm{CO}_{2}$ are produced (Table 1). $\gamma$-Valerolactone has previously been reported to decompose into $\mathrm{CO}_{2}$ and butene over a weak solid acid at a similar temperature [49]. However, under MTH conditions butadiene, $\mathrm{CO}$, and water are observed as the primary decomposition products from $\gamma$-valerolactone.

\subsection{Additive concentration}

Based on the data from Table 1 in combination with knowledge of very short lifetimes when reacting the pure compounds we speculated whether the lifetime improvement from dilution in methanol correlated linearly with the wt $\%$ of the additives or whether it was possible to convert more of the additive at suitable concentrations. To investigate this, the 4 most interesting compounds from Table 1 (methyl lactate, $\gamma$-valerolactone, glycerol, and acetic acid) were converted in different concentrations in methanol. These compounds can potentially be derived from biomass and possessed the ability to dissociate $\mathrm{CO} / \mathrm{CO}_{2}$. Figure 3 presents the conversion capacities of the additives diluted in methanol. Figure $3 \mathrm{a}$ and $3 \mathrm{~b}$ illustrate that reacting pure methyl lactate or pure $\gamma$ valerolactone results in very poor conversion capacities. However, looking at the lower levels of methyl lactate in the feed (Figure 3a) we clearly see that an optimum in the conversion capacity exists at a wt $\%$ of 10-25. Conclusively, the dilution of methanol does not only increase the lifetime proportionally to the dilution level but fine tuning the concentration leads to an increased total conversion capacity of methyl lactate before the catalyst is deactivated. The lower limit is rationalized by considering that when only small amounts of methyl lactate is added deactivation from conversion of methanol dominates. This means that even if the catalyst had a similar lifetime as for conversion of pure methanol, a $2.5 \mathrm{wt} \%$ solution of methyl lactate would not result in as high additive conversion as a feed in the $10-25 \mathrm{wt} \%$ range.

Figure $3 \mathrm{~b}$ shows a similar dilution behavior for converting $\gamma$-valerolactone as observed for methyl lactate. Also here an optimum exists in the conversion capacity, though it should be noted that the optimum is at a lower wt $\%$, namely around 5-10. In the case of glycerol (Figure 3c)the experiments revealed an optimum around 2.5-5 $\mathrm{wt} \%$ and high concentrations (above $50 \mathrm{wt} \%$ ) deactivate the catalyst so rapidly that we chose not to react pure glycerol under these reaction conditions. Glycerol has a very low effective $\mathrm{H} / \mathrm{C}$ ratio of 0.67 which correlates well with the low optimum level of addition and the rapid deactivation seen in Table 1. Furthermore, glycerol forms only modest amounts of $\mathrm{CO}$ and $\mathrm{CO}_{2}$ which support the fact that it is one of the most unwanted molecules to coconvert with methanol from a catalyst lifetime perspective.

For acetic acid a somewhat different trend is revealed. Increasing amounts of acetic acid in the feed results in a larger amount of $\mathrm{CO}_{2}$ which can be explained by increased tendency towards ketonization forming acetone and $\mathrm{CO}_{2}$ [28]. The conversion capacity of acetic acid thus increases with the concentration correlating with the fact that acetone does not induce massive deactivation (see Table 1). However, very early breakthrough of methyl acetate and acetic acid in the $25 \mathrm{wt} \%$ 
experiment complicates the quantitative interpretation and presumably a higher reaction temperature is required to reach a satisfactory conversion level. Acetic acid and methyl acetate appears alongside methanol and DME in the $10 \mathrm{wt} \%$ experiment.

\subsection{Product distribution}

Not only the conversion capacity but also changes in product selectivity are crucial when co-feeding various compounds. If the deoxygenation proceeds through dehydration and not through decarboxylation and decarbonylation the reaction will inevitably produce a more hydrogen deficient hydrocarbon product mixture. This point is rather important since it has previously been argued that the high aromatic content in MTH derived gasoline limits its implementation [50,51]. Table 2 lists the initial product selectivities as a function of increasing oxygenate addition. We note that reacting small amounts of additive leads to very similar product compositions as observed for pure methanol. However, with increasing amounts of additive a rise in the abundance of aromatics (mainly benzene, toluene, xylenes and tri-methylbenzenes) is observed at the cost of the $\mathrm{C}_{4+}$ aliphatic products while no oxygenated aromatic products are detected. This high selectivity towards aromatics at low methanol contents in the feed is supported by a recent report on direct conversion of glycerol over H-ZSM-5, where aromatics are produced in large amounts [25]. Further from Table 2 it is clear that the increasing selectivity towards aromatics comes alongside a decreasing $\mathrm{C}_{4}$-HTI. The low $\mathrm{C}_{4}$-HTI could be explained by the possibility of arene production without the necessity of co-production of alkanes due to the low effective $\mathrm{H} / \mathrm{C}$ ratio of the reaction mixture. It should be noted that in the high concentration experiments (with run times below one hour) the $\mathrm{C}_{4}$-HTI decreases rapidly with timeon-stream as deactivation is very pronounced.

With respect to the formation of $\mathrm{CO}$ and $\mathrm{CO}_{2}$ in the experiments concerning conversion of glycerol and acetic acid presented in Table 2, high concentration of the additive leads to the production of more $\mathrm{CO}$ and $\mathrm{CO}_{2}$ pr. mole of additive. This indicates that the decarboxylation/decarbonylation routes are favored at low methanol contents, which is in good correlation with a previous report [35]. This is also observed for low concentrations of methyl lactate and $\gamma$-valerolactone which indicate that this is a more general trend. Even though the amount of $\mathrm{CO}$ and $\mathrm{CO}_{2}$ produced pr. mole of additive increases at higher concentrations, this is not enough to offset the very low $\mathrm{H} / \mathrm{C}_{\mathrm{eff}}$ ratio at these feed compositions, and the hydrocarbon product mixture is thus very rich in aromatics.

\subsection{Isotopic labeling}

When $\mathrm{CO}$ or $\mathrm{CO}_{2}$ is formed, some carbon atoms are lost and do not enter the hydrocarbon products. The analysis of the product stream for $\mathrm{CO}$ and $\mathrm{CO}_{2}$ gives an indication of what is occurring but not whether the carbon atoms present in the additive do in fact end up in conventional gasoline products. In order to investigate this issue in detail ${ }^{13} \mathrm{C}$ labeled additives or ${ }^{13} \mathrm{C}$ labeled methanol was employed and the ${ }^{13} \mathrm{C}$ content in selected main products (butene, butane, pentane, pentene, toluene, xylene and trimethylbenzene) was analyzed in order to trace the carbon atoms from the additives. For labeling experiments we employed the additives investigated in Table 2 and the compounds were reacted in a concentration close to the previously defined optimum. In the case of glycerol and acetic acid, the additives were ${ }^{13} \mathrm{C}$ labeled whereas for methyl lactate and $\gamma$-valerolactone we used standard additives and ${ }^{13} \mathrm{C}$ labeled methanol. The experiments were conducted for $\sim 1$ hour corresponding to less than $1 / 10$ the total reaction time which makes the data representative for the initial product selectivities given in Table 1 and Table 2. During this time span no change in the pattern of ${ }^{13} \mathrm{C}$ incorporation was observed. 
Figure 4 presents results from the labeling experiments for glycerol, methyl lactate, acetic acid, and $\gamma$-valerolactone, respectively. Figure 4 a shows the ${ }^{13} \mathrm{C}$ content in the products when reacting $5 \mathrm{wt} \%$ of ${ }^{13} \mathrm{C}$ labeled glycerol in methanol. The dotted line represents the ${ }^{13} \mathrm{C}$ content in the feed. If all additive carbons were incorporated and distributed evenly in the products, $5.05 \%{ }^{13} \mathrm{C}$ would be expected in all products. Interestingly, we see that the aromatic products (toluene, xylene, and trimethylbenzene) actually contain significantly more ${ }^{13} \mathrm{C}$ than the average while the aliphatic products contain less. It thus appears that the reaction path of glycerol favors the formation of aromatics. Carbon atoms present in the aromatics will eventually equilibrate into the remaining products through alkene dissociation as described in detail elsewhere [52].This observation is in good agreement with a recent report where an increased affinity for aromatization is found for propanal compared to propanol when reacted over HZSM-5 [21], and the authors propose direct production of aromatics from propanal through a series of aldol condensation reactions and dehydrations. In the aliphatic compounds, only a small difference exists between incorporation into saturated and unsaturated compounds, but the longer pentane and pentene have a markedly lower content than their $\mathrm{C}_{4}$ analogues.

Figure $4 \mathrm{~b}$ presents data from conversion of $25 \mathrm{wt} \%$ methyl lactate in ${ }^{13} \mathrm{C}$ labeled methanol. From Table 2 it can be seen that methyl lactate splits off $\mathrm{CO}$ suggesting a loss of $1 / 4$ of the carbon atoms originally present in the molecule. The dotted lines in Figure $4 \mathrm{~b}$ represents the average ${ }^{13} \mathrm{C}$ content in the feed while the dashed line represent the expected ${ }^{13} \mathrm{C}$ content if only 3 of the carbon atoms in methyl lactate are incorporated into the hydrocarbon products. Note that the $\mathrm{Y}$-axis shows the ${ }^{12} \mathrm{C}$ content since ${ }^{13} \mathrm{C}$ labeled methanol is used instead of labeled additive in this experiment. As for glycerol, it is observed that the aromatic products contain more additive carbon compared to the aliphatic products and the $\mathrm{C}_{5}$ compounds contain less additive carbon than the $\mathrm{C}_{4}$ compounds. Further, the ${ }^{12} \mathrm{C}$ content of the individual products is located above and below the ${ }^{12} \mathrm{C}$ level for incorporation of 3 carbon atoms in correlation with the fact that one carbon atom from methyl lactate is removed by decarbonylation. At present we are unable to explain the lower incorporation into pentane compared to butane but we note that this trend is also present in the other experiments, though to a smaller extent.

Figure $4 \mathrm{c}$ shows data from the experiment co-reacting $10 \mathrm{wt} \%$ of ${ }^{13} \mathrm{C}$ labeled acetic acid in methanol. The pattern of ${ }^{13} \mathrm{C}$ incorporation with high levels in the aromatic compounds and less in the aliphatic is recognized. The total incorporation distributes below and above the ${ }^{13} \mathrm{C}$ content of the feed which means that the vast majority of even the acid carbon from acetic acid is likely incorporated into the hydrocarbon products. This is somewhat surprising since transfer of significant amounts of hydrogen to acetic acid $(\mathrm{H} / \mathrm{C}$ effective $=0)$ is required to produce these products. The aliphatic ${ }^{13} \mathrm{C}$ incorporation is somewhat inconsistent with the other experiments which can partly be explained by the reaction path of acetic acid described elsewhere [9,28]. Acetic acid can form acetone and further iso-butene in sequence. However only a relatively low amount of $\mathrm{CO}_{2}$ which would be formed in the ketonization reaction (producing acetone and $\mathrm{CO}_{2}$ ) was detected but it could be enough to enrich iso-butene above the expected value. Finally in Figure $4 \mathrm{~d} \gamma$-valerolactone was co-reacted with ${ }^{13} \mathrm{C}$ methanol. The results are very similar to what was observed when converting methyl lactate. Around $4 / 5$ of the carbon from the additive is incorporated into the products (predominantly into the aromatics) which corresponds well with the significant $\mathrm{CO}$ and $\mathrm{CO}_{2}$ formation observed.

From this type of GC-MS analysis it is not possible to analyze the ${ }^{13} \mathrm{C}$ content in the myriad of products formed in the reaction in order to calculate an average ${ }^{13} \mathrm{C}$ content in the gasoline product. However, based on the detected levels of $\mathrm{CO}$ and $\mathrm{CO}_{2}$ as well as the presented data on ${ }^{13} \mathrm{C}$ 
incorporation it seems likely that the majority of the carbon present in the additive, which do not form $\mathrm{CO}$ or $\mathrm{CO}_{2}$, does indeed end up in the hydrocarbon products. Presumably the different additives have individual reaction paths highly dependent on the specific concentration and we are only able to observe the composition after some equilibration (by cracking, isomerization, oligomerization etc.) over the full catalyst bed has occurred. To address the enrichment of additive carbon in the aromatic products we repeated the experiment with ${ }^{13} \mathrm{C}$ labeled acetic acid with lower amounts of catalyst in order to suppress secondary reactions. The results are given in Figure 5 and in all cases $>99 \%$ conversion of methanol/DME and acetic acid was observed.

Figure 5 reveals that as less catalyst is used, a pronounced decrease in the ${ }^{13} \mathrm{C}$ carbon $\%$ of the aliphatics is observed while the content is relatively unchanged in the aromatics products. It is also clear that less additive carbon is present in the saturated aliphatics compared to the corresponding olefins. These results support a reaction path where aliphatic products are not formed directly from acetic acid. Over an active catalyst the initially formed aromatic compounds will subsequently split off alkenes which through hydrogen transfer reactions can produce alkanes and thus distribute the additive carbon into all products.

\subsection{Temperature programmed oxidation (TPO)}

A catalyst deactivated in methanol conversion is able to catalyze the methanol-DME equilibrium yielding predominantly DME for numerous hours after hydrocarbons are no longer formed in significant amounts. In the case of $10 \mathrm{wt} \%$ of $\gamma$-valerolactone, methyl lactate, and glycerol in methanol the DME formation decreases rapidly after deactivation whereas DME is continually produced for conversion of acetic acid in methanol. Surprisingly, deactivating the catalyst with 10 $w t \%$ of anisole which shows the lowest conversion capacity of all the additives (see Table 1) does however not stop the production of DME. To investigate this observation, TPO on the catalysts used in the concentration series (from Table 2) as well as on selected catalysts from Table 1 was performed in order to determine the amount of coke present on the catalyst at full deactivation.

Bilbao and co-workers have done thorough coke analyses for conversion of bio-oil diluted in methanol over H-ZSM-5 and reported a distinction between thermal and catalytic coke. The thermal coke which has a higher $\mathrm{H} / \mathrm{C}$ ratio was attributed to bio-oil and could be combusted at a lower temperature compared to coke from a conventional methanol experiment $[18,34]$.

Figure 6 shows the results from TPO experiments of the concentration series from Table 2 and it is clear that the total amount of coke deposited on the deactivated catalyst decreases as the wt $\%$ of additive is increased. We were however unable to correlate the combustion temperature to specific types of coke on the catalysts but merely note that a catalyst employed in the conversion of methanol for less than an hour (the lifetime of experiments having $\geq 50 \mathrm{wt} \%$ of additive) contain very small amounts of coke $(\sim 1 \%)$ which underline that conversion of the hydrogen deficient additives from Table 1 results in excessive coke formation. No clear trend in levels of coke deposition was observed from the experiments in Table 1 where most catalysts contained approximately $10 \mathrm{wt} \%$ carbon although catalysts from conversion of $10 \mathrm{wt} \%$ anisole or dimethoxybenzene contained slightly less $(\sim 8 \mathrm{wt} \%)$.

\section{Conclusions}


We have investigated the co-conversion of various model compounds in methanol under MTH reaction conditions which represents an alternative strategy to simply using "green" additives to conventional gasoline. The effective $\mathrm{H} / \mathrm{C}$ ratio has previously been used as an indicator of whether an oxygenate would lead to rapid deactivation and we confirm the overall tendency of pronounced deactivation for conversion of compounds with low effective $\mathrm{H} / \mathrm{C}$ ratios. However, the catalytic data also shows that structural isomers can indeed perform very differently with respect to conversion capacity and selectivity. Molecules capable of dissociating $\mathrm{CO}_{2}$ or $\mathrm{CO}$ generally experience higher conversion capacities highlighting that consideration of the specific functionalities present in the additive is crucial in order to understand the reactivity. Converting the pure compounds leads to very short lifetimes of the zeolite catalyst and depending on the molecule an optimal dilution in methanol can result in up to 10 times higher conversion capacities of the additive before deactivation of the catalyst.

Experiments using ${ }^{13} \mathrm{C}$ labeling show that the carbon atoms from the additives are distributed into the hydrocarbon products with a high affinity for the aromatics. We can thus rule out that the additive carbon ends up in single "dead end" hydrocarbons or form new unconvertible oxygenates.

The results presented here give new understanding of the reactivity of different oxygenates when converted to hydrocarbons over H-ZSM-5, and might help pave the road for development of new processes for conversion of biomass to hydrocarbon-based fuels and chemicals.

\section{Acknowledgements}

The Center for Sustainable and Green Chemistry is sponsored by the Danish National Research Foundation. 


\begin{tabular}{|c|c|c|c|c|c|c|c|c|c|}
\hline Additive & $\begin{array}{l}\text { Eff. } \mathbf{H} / \mathbf{C} \\
\text { (additive) }\end{array}$ & $\begin{array}{l}\text { Conversion } \\
\text { Capacity }^{\text {a }}\end{array}$ & $\begin{array}{l}\mathrm{C}_{4-} \\
\text { HTI }^{\mathrm{c}}\end{array}$ & $\mathrm{CO}^{\mathrm{b}}$ & $\mathrm{CO}_{2}{ }^{\mathrm{b}}$ & $\mathrm{C}_{1-3}^{\mathrm{c}}$ & $\mathrm{C}_{4}{ }^{\mathrm{c}}$ & $\begin{array}{l}\mathbf{C}_{5+} \mathbf{c} \\
\text { (aliphatic) }\end{array}$ & $\begin{array}{l}\mathbf{C}_{6-10} \mathbf{c} \\
\text { (aromatic) }\end{array}$ \\
\hline $\mathrm{H}_{2} \mathrm{O}$ & - & 512 & 0.36 & $0 \%$ & $0 \%$ & $22 \%$ & $28 \%$ & $31 \%$ & $19 \%$ \\
\hline Methanol & 2 & 471 & 0.38 & $0 \%$ & $0 \%$ & $22 \%$ & $28 \%$ & $31 \%$ & $19 \%$ \\
\hline Formaldehyde dimethyl acetal & 1.33 & 62 & 0.34 & $0 \%$ & $0 \%$ & $22 \%$ & $25 \%$ & $28 \%$ & $25 \%$ \\
\hline Formic acid & -2 & 496 & 0.38 & $85 \%$ & $2 \%$ & $22 \%$ & $28 \%$ & $32 \%$ & $18 \%$ \\
\hline Ethanol & 2 & 487 & 0.36 & $0 \%$ & $0 \%$ & $24 \%$ & $27 \%$ & $31 \%$ & $18 \%$ \\
\hline Ethyleneglycol & 1 & 131 & 0.31 & $4 \%$ & $0 \%$ & $23 \%$ & $24 \%$ & $25 \%$ & $28 \%$ \\
\hline Acetaldehyde & 1 & 72 & 0.29 & $7 \%$ & $0 \%$ & $26 \%$ & $23 \%$ & $22 \%$ & $29 \%$ \\
\hline Acetic acid & 0 & 91 & 0.26 & $5 \%$ & $3 \%$ & $21 \%$ & $20 \%$ & $23 \%$ & $36 \%$ \\
\hline $\begin{array}{l}\text { Glycolaldehyde dimethyl } \\
\text { acetal }\end{array}$ & 1 & 40 & 0.31 & $43 \%$ & $3 \%$ & $23 \%$ & $26 \%$ & $28 \%$ & $23 \%$ \\
\hline Methyl glycolate & 0 & 86 & 0.34 & $91 \%$ & $0 \%$ & $23 \%$ & $25 \%$ & $26 \%$ & $26 \%$ \\
\hline 2-Propanol & 2 & 578 & 0.38 & $0 \%$ & $0 \%$ & $21 \%$ & $28 \%$ & $32 \%$ & $19 \%$ \\
\hline 1,2-Propanediol & 1.33 & 190 & 0.32 & $1 \%$ & $0 \%$ & $21 \%$ & $25 \%$ & $29 \%$ & $25 \%$ \\
\hline 1,3-Propanediol & 1.33 & 96 & 0.33 & $1 \%$ & $0 \%$ & $22 \%$ & $25 \%$ & $28 \%$ & $25 \%$ \\
\hline Glycerol & 0.67 & 44 & 0.33 & $8 \%$ & $0 \%$ & $24 \%$ & $23 \%$ & $25 \%$ & $28 \%$ \\
\hline Acetone $^{\mathrm{d}}$ & 1.33 & 271 & 0.29 & $0 \%$ & $1 \%$ & $22 \%$ & $24 \%$ & $26 \%$ & $27 \%$ \\
\hline Propionaldehyde & 1.33 & 138 & 0.31 & $3 \%$ & $0 \%$ & $22 \%$ & $24 \%$ & $26 \%$ & $28 \%$ \\
\hline Propionic acid & 0.67 & 109 & 0.30 & $26 \%$ & $4 \%$ & $22 \%$ & $24 \%$ & $25 \%$ & $29 \%$ \\
\hline Methyl lactate & 0.5 & 189 & 0.33 & $93 \%$ & $0 \%$ & $21 \%$ & $25 \%$ & $28 \%$ & $26 \%$ \\
\hline Methyl acrylate & 0.5 & 27 & 0.27 & $26 \%$ & $10 \%$ & $24 \%$ & $22 \%$ & $25 \%$ & $29 \%$ \\
\hline 1-Butanol & 2 & 679 & 0.39 & $0 \%$ & $0 \%$ & $20 \%$ & $27 \%$ & $32 \%$ & $21 \%$ \\
\hline 1,4-Butanediol & 1.5 & 139 & 0.33 & $0 \%$ & $0 \%$ & $22 \%$ & $25 \%$ & $27 \%$ & $26 \%$ \\
\hline 1,3-Butanediol & 1.5 & 120 & 0.33 & $0 \%$ & $0 \%$ & $23 \%$ & $26 \%$ & $27 \%$ & $24 \%$ \\
\hline 1,2-Butanediol & 1.5 & 166 & 0.33 & n.a. & n.a. & $22 \%$ & $26 \%$ & $28 \%$ & $24 \%$ \\
\hline 2,3-Butanediol ${ }^{\mathrm{d}}$ & 1.5 & 320 & 0.31 & $0 \%$ & $0 \%$ & $22 \%$ & $25 \%$ & $29 \%$ & $24 \%$ \\
\hline Butyraldehyde & 1.5 & 146 & 0.34 & $5 \%$ & $0 \%$ & $22 \%$ & $25 \%$ & $27 \%$ & $26 \%$ \\
\hline Butanone $^{d}$ & 1.5 & 327 & 0.27 & $0 \%$ & $0 \%$ & $23 \%$ & $25 \%$ & $26 \%$ & $25 \%$ \\
\hline Butyric acid & 1 & 219 & 0.35 & $62 \%$ & $0 \%$ & $21 \%$ & $25 \%$ & $30 \%$ & $24 \%$ \\
\hline 1,5-Pentanediol & 1.6 & 299 & 0.34 & $0 \%$ & $0 \%$ & $22 \%$ & $25 \%$ & $28 \%$ & $25 \%$ \\
\hline Levulinic acid & 0.4 & 37 & 0.29 & $90 \%$ & $0 \%$ & $24 \%$ & $25 \%$ & $25 \%$ & $26 \%$ \\
\hline$\gamma$-Valerolactone & 0.8 & 82 & 0.33 & $78 \%$ & $7 \%$ & $22 \%$ & $26 \%$ & $28 \%$ & $24 \%$ \\
\hline 2-methyl-tetrahydrofuran & 1.6 & 255 & 0.36 & $0 \%$ & $0 \%$ & $20 \%$ & $25 \%$ & $29 \%$ & $26 \%$ \\
\hline Toluene & 1.14 & 412 & 0.33 & $0 \%$ & $0 \%$ & $19 \%$ & $20 \%$ & $21 \%$ & $40 \%$ \\
\hline Anisole & 0.86 & 10 & na. & $0 \%$ & $0 \%$ & $26 \%$ & $21 \%$ & $21 \%$ & $32 \%$ \\
\hline 1,2-dimethoxybenzene & 0.75 & 9 & na. & $0 \%$ & $0 \%$ & $28 \%$ & $20 \%$ & $26 \%$ & $26 \%$ \\
\hline
\end{tabular}

${ }^{\mathrm{a}} \mathrm{g}_{\text {feed }} / \mathrm{g}_{\text {zeolite }},{ }^{\mathrm{b}} \mathrm{mol} / \mathrm{mol}_{\text {additive }},{ }^{c}$ initial, ${ }^{\mathrm{d}}$ breakthrough of additive before DME/methanol

Table 1. Conversion capacity, initial selectivity, $\mathrm{C}_{4}-\mathrm{HTI}$, and $\mathrm{CO} / \mathrm{CO}_{2}$ production from conversion of various oxygenates as $10 \%$ solutions in methanol $\left(\mathrm{T}=370{ }^{\circ} \mathrm{C}, \mathrm{P}=1 \mathrm{bar}, 300 \mathrm{mg} \mathrm{H}-\mathrm{ZSM}-5\right.$, WHSV $=8 \mathrm{~h}^{-1}$ ) 


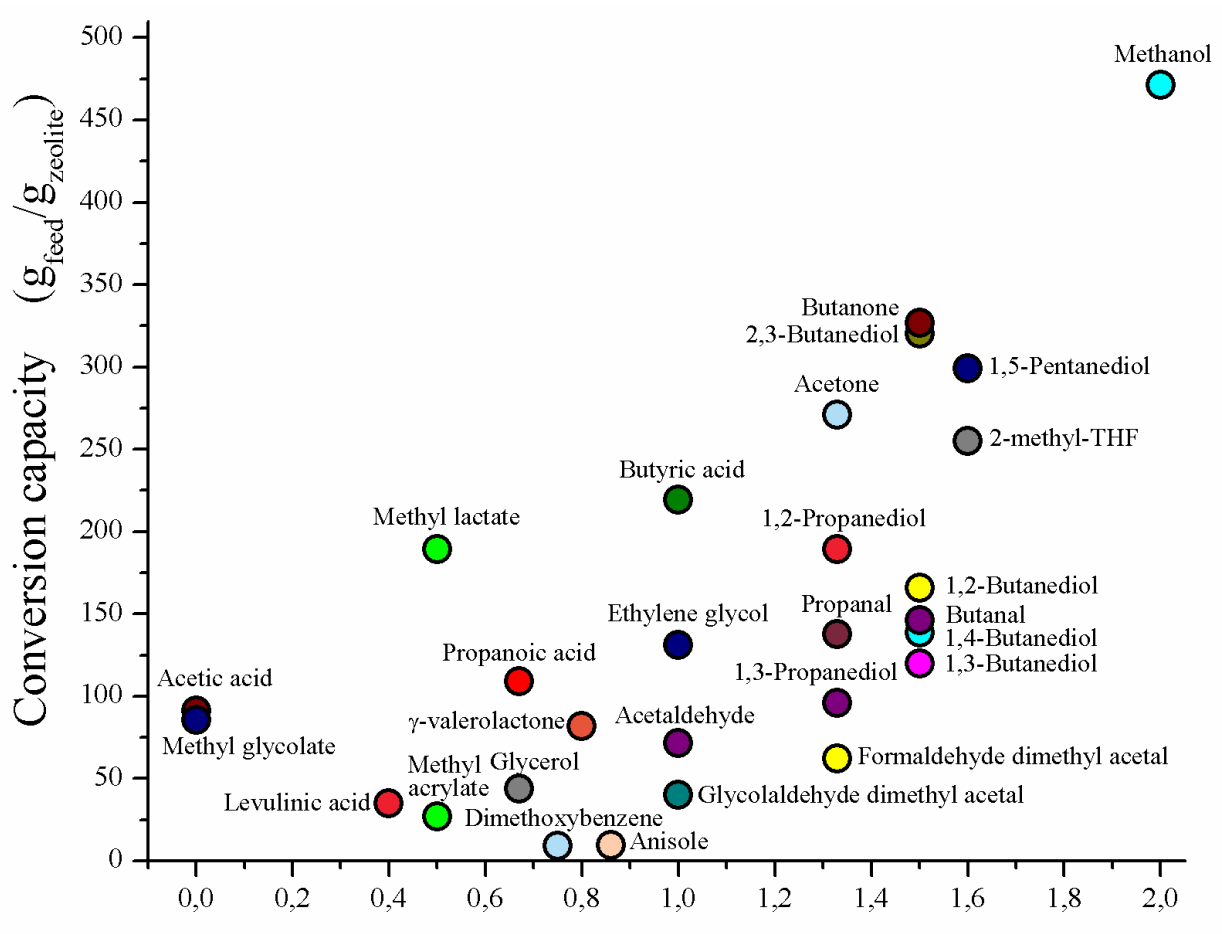

Effective $\mathrm{H} / \mathrm{C}$ ratio of additive

Figure 1. Total conversion capacity from experiments having $10 \mathrm{wt} \%$ of additive in methanol plotted as a function of the effective $\mathrm{H} / \mathrm{C}$ ratio of the additive $\left(\mathrm{T}=370^{\circ} \mathrm{C}, \mathrm{P}=1 \mathrm{bar}, 300 \mathrm{mg} \mathrm{H}-\mathrm{ZSM}-5\right.$, $\mathrm{WHSV}=8 \mathrm{~h}^{-1}$ ).

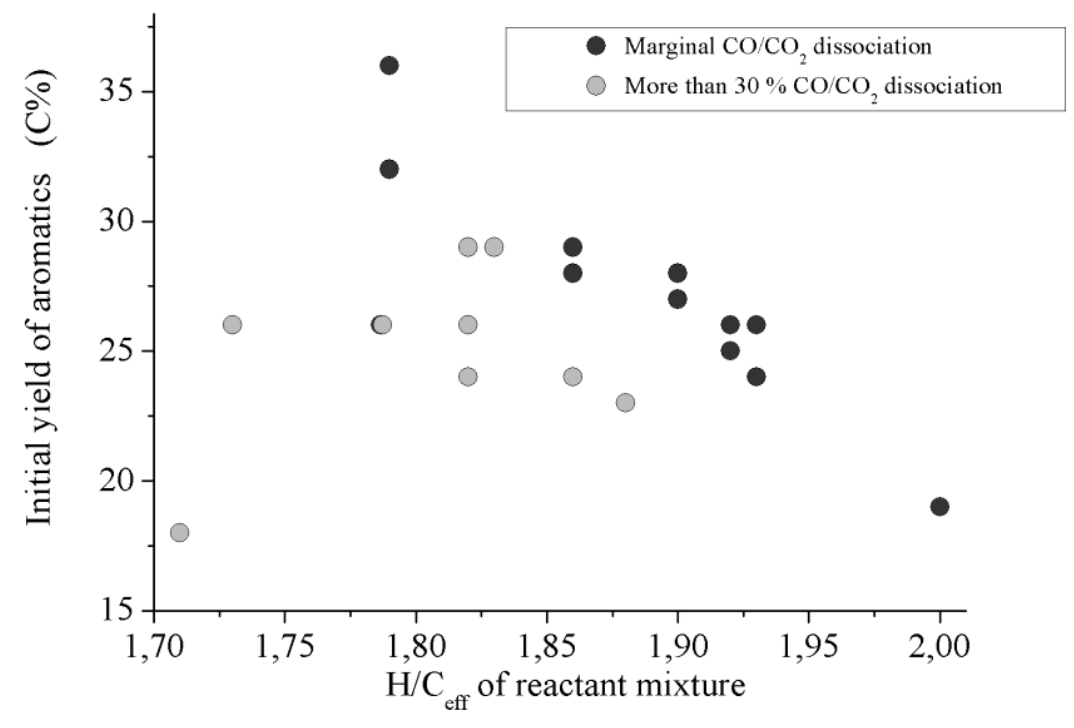

Figure 2. Initial aromatic carbon \% plotted as a function of the effective $\mathrm{H} / \mathrm{C}$ ratio of the reactant mixture $\left(\mathrm{T}=370^{\circ} \mathrm{C}, \mathrm{P}=1\right.$ bar, $300 \mathrm{mg} \mathrm{H}-Z \mathrm{SM}-5$, WHSV $\left.=8 \mathrm{~h}^{-1}\right)$. 

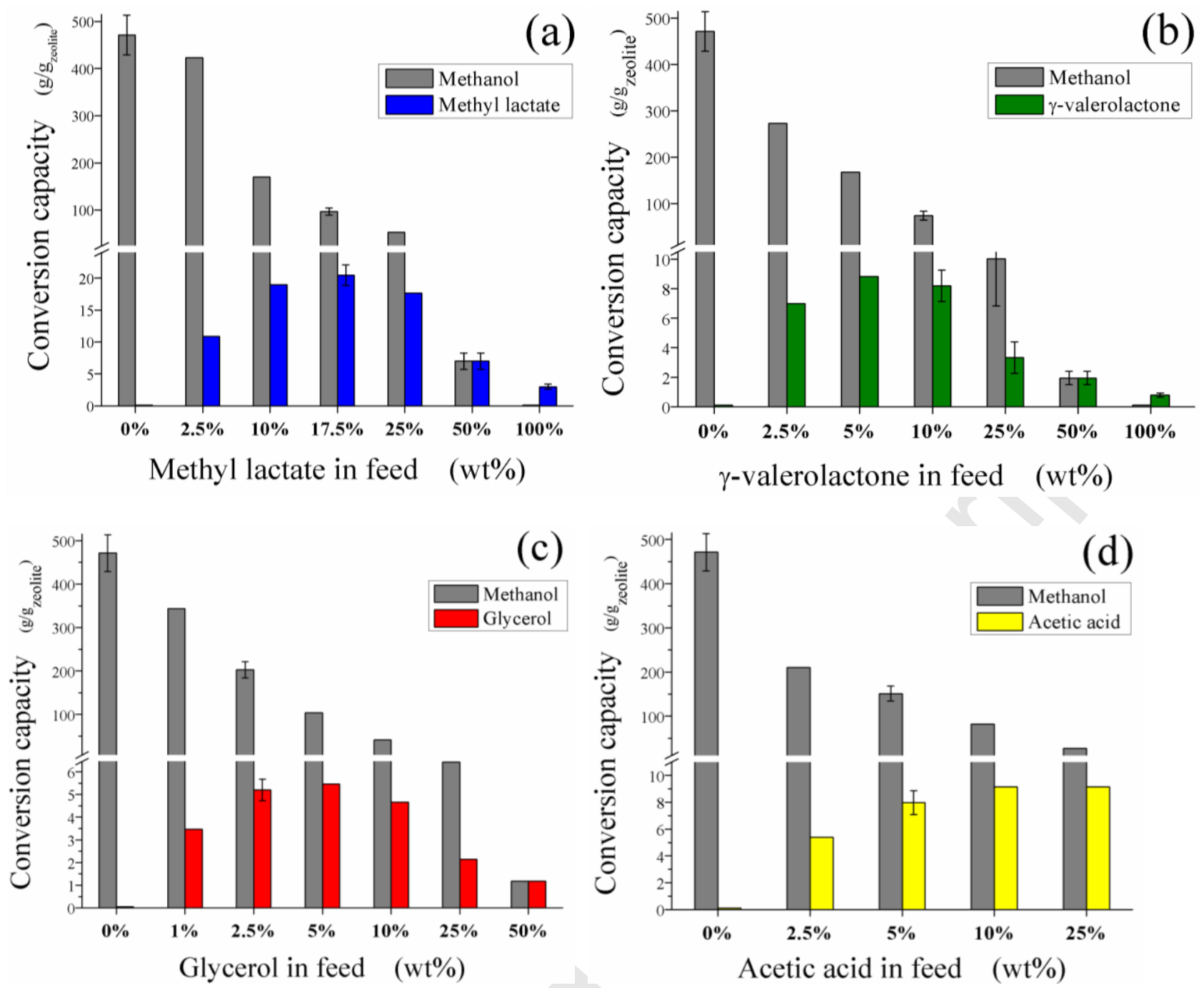

Figure 3. Conversion capacities plotted at different $w t \%$ of additive in the feed. (a) methyl lactate, (b) $\gamma$-valerolactone, (c) glycerol and (d) acetic acid. Error bars represent \pm 2 standard deviations. Note the different scales below the break $\left(\mathrm{T}=370^{\circ} \mathrm{C}, \mathrm{P}=1\right.$ bar, $300 \mathrm{mg} \mathrm{H}-\mathrm{ZSM}-5$, WHSV $\left.=8 \mathrm{~h}^{-1}\right)$. 


\begin{tabular}{|c|c|c|c|c|c|c|c|c|c|}
\hline Additive & wt $\%$ & $\begin{array}{l}\text { Eff. } \mathrm{H} / \mathrm{C} \\
\text { of feed }^{\mathrm{a}}\end{array}$ & $\mathrm{C}_{4}-\mathrm{HTI}^{\mathrm{b}}$ & $\mathrm{CO}^{\mathrm{c}}$ & $\mathrm{CO}_{2}{ }^{\mathrm{c}}$ & $C_{1-3}^{b}$ & $\mathrm{C}_{4}{ }^{\mathrm{b}}$ & $\begin{array}{l}\mathbf{C}_{5+}^{\mathbf{b}} \\
\text { (aliphatic) }\end{array}$ & $\begin{array}{l}\mathbf{C}_{6-10} \mathbf{b}^{-} \\
\text {(aromatic) }\end{array}$ \\
\hline Methanol & - & 2 & 0.38 & $0 \%$ & $0 \%$ & $22 \%$ & $28 \%$ & $31 \%$ & $19 \%$ \\
\hline Acetic acid & $2.5 \%$ & 1.95 & 0.34 & $0 \%$ & $0 \%$ & $24 \%$ & $26 \%$ & $28 \%$ & $22 \%$ \\
\hline Acetic acid & $5 \%$ & 1.89 & 0.31 & $4 \%$ & $4 \%$ & $24 \%$ & $24 \%$ & $26 \%$ & $26 \%$ \\
\hline Acetic acid & $10 \%$ & 1.79 & 0.27 & $5 \%$ & $3 \%$ & $21 \%$ & $20 \%$ & $23 \%$ & $36 \%$ \\
\hline Acetic acid & $25 \%$ & 1.48 & 0.19 & $6 \%$ & $9 \%$ & $21 \%$ & $12 \%$ & $13 \%$ & $53 \%$ \\
\hline Glycerol & $1 \%$ & 1.99 & 0.38 & $0 \%$ & $0 \%$ & $22 \%$ & $27 \%$ & $30 \%$ & $21 \%$ \\
\hline Glycerol & $2.5 \%$ & 1.97 & 0.36 & $0 \%$ & $0 \%$ & $23 \%$ & $27 \%$ & $29 \%$ & $21 \%$ \\
\hline Glycerol & $5 \%$ & 1.93 & 0.34 & $10 \%$ & $0 \%$ & $24 \%$ & $26 \%$ & $27 \%$ & $23 \%$ \\
\hline Glycerol & $10 \%$ & 1.86 & 0.30 & $11 \%$ & $0 \%$ & $24 \%$ & $23 \%$ & $25 \%$ & $28 \%$ \\
\hline Glycerol & $25 \%$ & 1.66 & 0.23 & $16 \%$ & $2 \%$ & $23 \%$ & $20 \%$ & $20 \%$ & $37 \%$ \\
\hline Glycerol & $50 \%$ & 1.32 & na. $^{\mathrm{d}}$ & $21 \%$ & $3 \%$ & $24 \%$ & $15 \%$ & $16 \%$ & $45 \%$ \\
\hline Methyl lactate & $2.5 \%$ & 1.95 & 0.39 & $70 \%$ & $0 \%$ & $21 \%$ & $26 \%$ & $30 \%$ & $23 \%$ \\
\hline Methyl lactate & $10 \%$ & 1.82 & 0.33 & $93 \%$ & $0 \%$ & $21 \%$ & $25 \%$ & $28 \%$ & $26 \%$ \\
\hline Methyl lactate & $17.5 \%$ & 1.69 & 0.31 & $>95 \%$ & $1 \%$ & $23 \%$ & $24 \%$ & $26 \%$ & $27 \%$ \\
\hline Methyl lactate & $25 \%$ & 1.56 & 0.27 & $>95 \%$ & $1 \%$ & $23 \%$ & $22 \%$ & $23 \%$ & $32 \%$ \\
\hline Methyl lactate & $50 \%$ & 1.17 & 0.20 & $>95 \%$ & $1 \%$ & $25 \%$ & $17 \%$ & $17 \%$ & $41 \%$ \\
\hline Methyl lactate & $100 \%$ & 0.50 & na. $^{\mathrm{d}}$ & na. $^{\mathrm{d}}$ & na. $^{\mathrm{d}}$ & $26 \%$ & $7 \%$ & $6 \%$ & $61 \%$ \\
\hline$\gamma$-Valerolactone & $2.5 \%$ & 1.95 & 0.39 & $76 \%$ & $<2 \%$ & $24 \%$ & $27 \%$ & $28 \%$ & $21 \%$ \\
\hline$\gamma$-Valerolactone & $5 \%$ & 1.91 & 0.38 & $78 \%$ & $6 \%$ & $22 \%$ & $27 \%$ & $29 \%$ & $22 \%$ \\
\hline$\gamma$-Valerolactone & $10 \%$ & 1.82 & 0.32 & $78 \%$ & $7 \%$ & $22 \%$ & $26 \%$ & $28 \%$ & $24 \%$ \\
\hline$\gamma$-Valerolactone & $25 \%$ & 1.58 & 0.27 & $73 \%$ & $9 \%$ & $23 \%$ & $23 \%$ & $25 \%$ & $29 \%$ \\
\hline$\gamma$-Valerolactone & $50 \%$ & 1.26 & 0.24 & $72 \%$ & $11 \%$ & $21 \%$ & $20 \%$ & $19 \%$ & $40 \%$ \\
\hline$\gamma$-Valerolactone & $100 \%$ & 0.80 & na. $^{\mathrm{d}}$ & na. $^{\mathrm{d}}$ & na. $^{\mathrm{d}}$ & $17 \%$ & $16 \%$ & $15 \%$ & $52 \%$ \\
\hline
\end{tabular}

${ }^{a}$ calculated from the dehydrated $\mathrm{H} / \mathrm{C}$ ratios, ${ }^{b}$ initial, ${ }^{c} \mathrm{~mol} / \mathrm{mol}_{\text {additive }}{ }^{\mathrm{d}}$ too rapid catalyst deactivation to obtain data

Table 2. Initial selectivity, $\mathrm{C}_{4}-\mathrm{HTI}$, and $\mathrm{CO} / \mathrm{CO}_{2}$ production from conversion of different concentrations of various oxygenates in methanol $\left(\mathrm{T}=370^{\circ} \mathrm{C}, \mathrm{P}=1\right.$ bar, $300 \mathrm{mg} \mathrm{H}-\mathrm{ZSM}-5$, WHSV $=8 \mathrm{~h}^{-1}$ ). 

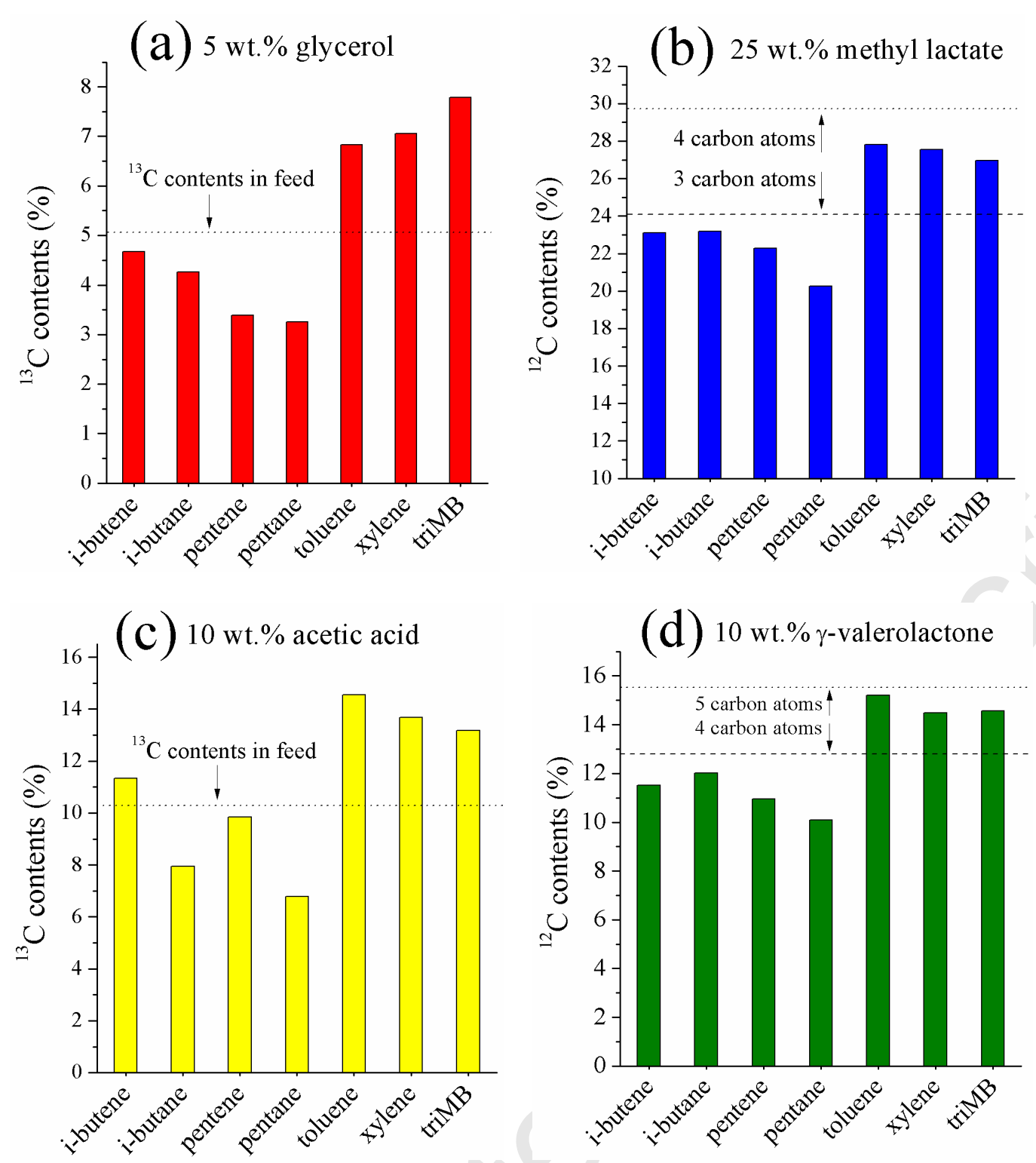

Figure $4 .{ }^{13} \mathrm{C}$ and ${ }^{12} \mathrm{C}$ content observed in typical main products of MTH. In the case of (a) $5 \mathrm{wt} \%$ glycerol and (c) $10 \mathrm{wt} \%$ acetic acid ${ }^{13} \mathrm{C}$ labeled additives in unlabeled methanol were used. In the case of (b) $25 \mathrm{wt} \%$ methyl lactate and (d) $10 \mathrm{wt} \% \gamma$-valerolactone ${ }^{13} \mathrm{C}$ methanol was used. The dotted lines correspond to the ${ }^{13} \mathrm{C}$ content in the feed while the dashed lines in (b) and (d) correspond to incorporation of all additive carbon after dissociation of 1 mole of $\mathrm{CO}$ or $\mathrm{CO}_{2}\left(\mathrm{~T}=370{ }^{\circ} \mathrm{C}, \mathrm{P}=1\right.$ bar, $300 \mathrm{mg}$ H-ZSM-5, WHSV $=8 \mathrm{~h}^{-1}$ ). 


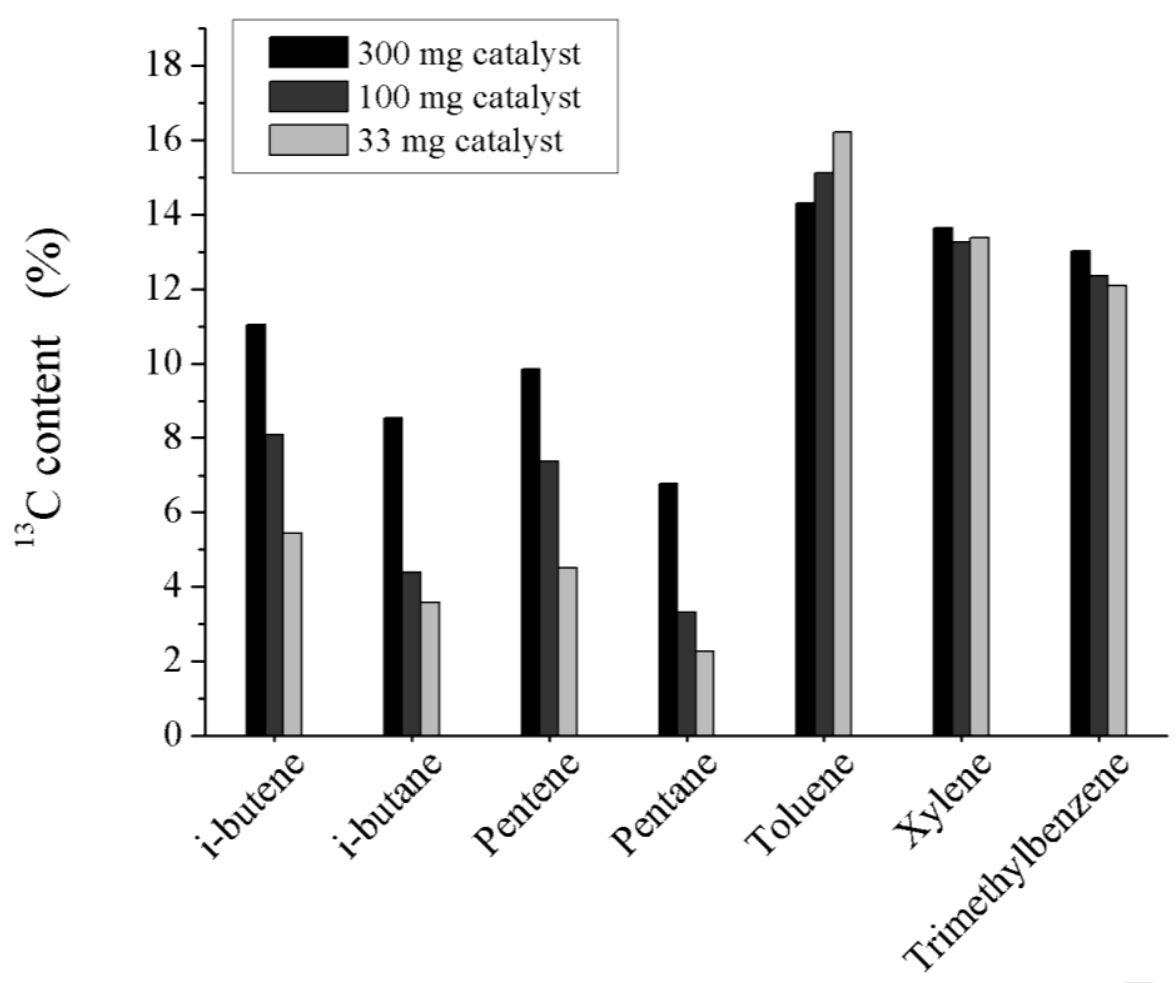

Figure $5 .{ }^{13} \mathrm{C}$ content in selected products from conversion of $10 \%{ }^{13} \mathrm{C}$ labeled acetic acid in methanol over $300 \mathrm{mg}\left(\right.$ WHSV $\left.=8 \mathrm{~h}^{-1}\right), 100 \mathrm{mg}\left(\mathrm{WHSV}=24 \mathrm{~h}^{-1}\right)$, or $33 \mathrm{mg}\left(\mathrm{WHSV}=72 \mathrm{~h}^{-1}\right)$ of catalyst $\left(\mathrm{T}=370^{\circ} \mathrm{C}, \mathrm{P}=1\right.$ bar $)$.
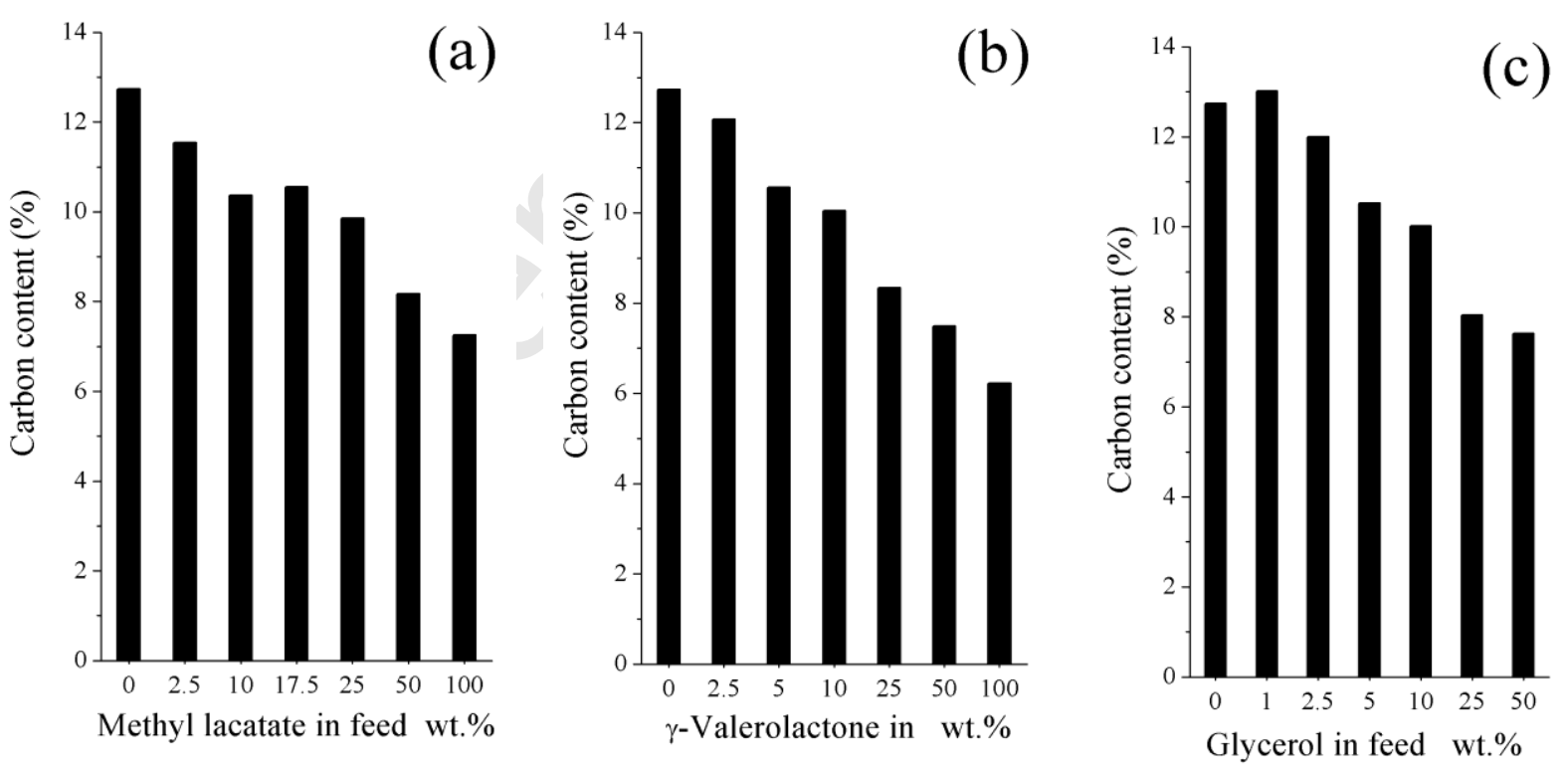

Figure 6. Data obtained from TPO experiments presenting the amount of carbon deposited on the fully deactivated catalysts upon conversion of different concentrations of additive in methanol. (a) methyl lactate, (b) $\gamma$-valerolactone, and (c) glycerol $\left(\mathrm{T}=370^{\circ} \mathrm{C}, \mathrm{P}=1 \mathrm{bar}, 300 \mathrm{mg} \mathrm{H}-\mathrm{ZSM}-5\right.$, $\mathrm{WHSV}=8 \mathrm{~h}^{-1}$ ). 


\section{References}

[1] G. W. Huber, S. Iborra, A. Corma, Chem. Rev. 106 (2006) 4044-4098.

[2] J. R. Regalbuto, Science 325 (2009) 822-824.

[3] A. Demirbas, Energy Convers. Manage. 50 (2009) 2239-2249.

[4] A. V. Bridgewater, M. L. Cottam, Energy Fuels 6 (1992) 113-120.

[5] S. Czernik, A. V. Bridgwater, Energy Fuels 18 (2004) 590-598.

[6] D. Mohan, C. U. Pittman, P. H. Steele, Energy fuels 20 (2006) 848-889.

[7] R. French, S. Czernik, Fuel Process. Technol. 91 (2010) 25-32.

[8] M. Stöcker, Microporous Mesoporous Mater. 29 (1999) 3-48.

[9] C. D. Chang, A. J. Silvestri, J. Catal. 47 (1977) 249-259.

[10] P. B. Weisz, W. O. Haag, P. G. Rodewald, Science 206 (1979) 57-58.

[11] N. Y. Chen, T. F. Degan Jr., L. R. Koenig, Chemtech 16 (1986) 506-511.

[12] P. D. Chantal, S. Kaliaguine, J. L. Grandmaison, A. Mahay, Appl. Catal. 10 (1984) 317-332.

[13] P. A. Horne, P. T. J. Williams, Anal. Appl. Pyrolysis 34 (1995) 65-85.

[14] J. D. Adjaye, N. N. Bakhshi, Fuel Process. Technol. 45 (1995) 185-202.

[15] R. K. Sharma, N. N. Bakhshi, Fuel Process. Technol. 35 (1993) 201-218.

[16] P. T. Williams, A. J. J. Brindle, Anal. Appl. Pyrolysis 67 (2003) 143-164.

[17] T. P. Vispute, H. Zhang, A. Sanna, R. Xiao, G. W. Huber, Science 330 (2010) 1222-1227. 
[18] A. G. Gayubo, A. T. Aguayo, A. Atutxa, B. Valle, J. J. Bilbao, Chem. Technol. Biotechnol. 80 (2005) 1244-1251.

[19] P. A. Horne, P. T. Williams, Renewable Energy 7 (1996) 131-144.

[20] X. Zhu, R. G. Mallinson, D. E. Resasco, Appl. Catal. A 379 (2010) 172-181.

[21] T. Q. Hoang, X. Zhu, T. Sooknoi, D. E. Resasco, R. G. Mallinson, J. Catal. 271 (2010) 201208.

[22] M. C. Samolada, A. Papafotica, I. Vasalos, Energy Fuels 14 (2000) 1161-1167.

[23] P. D. Chantal, S. Kaliaguine, J. L. Grandmaison, Appl. Catal. 18 (1985) 133-145.

[24] J. L. Grandmaison, P. D. Chantal, S. C. Kaliaguine, Fuel 69 (1990) 1058-1061.

[25] T. Q. Hoang, X. Zhu, T. Danuthai, L. L. Lobban, D. E. Resasco, R. G. Mallinson, Energy Fuels 24 (2010) 3804-3809.

[26] R. J. Evans, T. Milne, ACS Symposium Series 376 (1988) 311-327.

[27] T. Q Hoang, X. Zhu, L. L. Lobban, D. E. Resasco, R. G. Mallinson, Catal. Commun. 11 (2010) 977-981.

[28] G. J. Hutchings, P. Johnston, D. F. Lee, A. Warwick, C. D. Williams, M. Wilkinson, J. Catal. 147 (1994) 177-185.

[29] A. G. Gayubo, A. T. Aguayo, A. Atutxa, R. Aguado, J. Bilbao, Ind. Eng. Chem. Res. 43 (2004) 2610-2618.

[30] A. G. Gayubo, A. T. Aguayo, A. Atutxa, R. Aguado, M. Olazar, J. Bilbao, Ind. Eng. Chem. Res. 43 (2004) 2619-2626.

[31] J. D. Adjaye, N. N. Bakhshi, Biomass Bioenergy 8 (1995) 131-149. 
[32] L. H. Dao, M. Haniff, A. Houle, D. Lamothe, 193. National Meeting of the American Chemical Society 32:2 (1987) 308-316.

[33] R. K. Sharma, N. N. Bakhshi, Bioresour. Technol. 35 (1991) 57-66.

[34] A. G. Gayubo, B. Valle, A. T. Aguayo, M. Olazar, J. Bilbao, Energy Fuels 23 (2009) 41294136.

[35] A. G. Gayubo, B. Valle, A. T. Aguayo, M. Olazar, J. Bilbao, Ind. Eng. Chem. Res. 49 (2010) 123-131.

[36] B. Valle, A. G. Gayubo, A. Alonso, A. T. Aguayo, J. Bilbao, Appl. Catal. B 100 (2010) 318327.

[37] A. Corma, G. W. Huber, L. Sauvanaud, P. O’Connor, J. Catal. 247 (2007) 307-327.

[38] A. Corma, G. W. Huber, L. Sauvanaud, P. O’Connor, J. Catal. 257 (2008) 163-171.

[39] I. Graca, F. R. Ribeiro, H. S. Cerqueira, Y. L. Lam, M. B. B. de Almeida, Appl. Catal. B 90 (2009) 556-563.

[40] T. R. Carlson, T. P. Vispute, G. W. Huber, ChemSusChem 1 (2008) 397-400.

[41] T. R. Carlson, G. A. Tompsett, W. C. Conner, G. W. Huber, Top. Catal. 52 (2009) 241-252.

[42] T. R. Carlson, J. Jae, Y.-C. Lin, G. A. Tompsett, G. W. Huber, J. Catal. 270 (2010) 110-124.

[43] M. Bjørgen, F. Joensen, M. S. Holm, U. Olsbye, K.-P. Lillerud, S. Svelle, Appl. Catal. A 345 (2008) 43-50.

[44] T. V. W. Janssens, J. Catal. 264 (2009) 130-137.

[45] U. V. Mentzel, S. Shunmugavel, S. L. Hruby, C. H. Christensen, M. S. Holm, J. Am. Chem. Soc. 131 (2009) 17009-17013. 
[46] H. Heeres, R. Handana, D. Chunai, C. B. Rasrendra, B. Girisuta, H. J. Heeres, Green Chem. 11 (2009) 1247-1255.

[47] H. Mehdi, V. Fabos, R. Tuba, A. Bodor, L. T. Mika, I. T. Horvath, Top. Catal. 48 (2008) 4954.

[48] B. Kartryniok, S. Paul, F. Dumeignil, Green Chem. 12 (2010) 1910-1913.

[49] J. Q. Bond, D. M. Alonso, D. Wang, R. M. West, J. A. Dumesic, Science 327 (2010) 11101114.

[50] J. F. Haw, D. M. Marcus, Top. Catal. 34 (2005) 41-48.

[51] J. F. Haw, D. M. Marcus, Nanotechnology in Catalysis, Plenum Publishers, New York, 2004, Vol. 1, Chapter 13.

[52] M. Bjørgen, S. Svelle, F. Joensen, J. Nerlov, S. Kolboe, F. Binino, L. Palumbo, S. Bordiga, U. Olsbye, J. Catal. 249 (2007) 195-207. 


\begin{tabular}{|c|c|c|c|c|c|c|c|c|c|}
\hline Additive & $\begin{array}{l}\text { Eff. H/C } \\
\text { (additive) }\end{array}$ & $\begin{array}{l}\text { Conversio } \\
\text { n } \\
\text { Capacity }^{\text {a }}\end{array}$ & $\begin{array}{l}\mathrm{C}_{4^{-}} \\
\text {HTI }^{\mathrm{c}}\end{array}$ & $\mathbf{C O}^{\mathbf{b}}$ & $\mathrm{CO}_{2}{ }^{\mathrm{b}}$ & $\mathrm{C}_{1-3}^{\mathrm{c}}$ & $\mathrm{C}_{4}{ }^{\mathrm{c}}$ & $\begin{array}{l}\mathbf{C}_{5+}{ }^{\mathbf{c}} \\
\text { (aliphatic } \\
\text { ) }\end{array}$ & $\begin{array}{l}\mathbf{C}_{6-10}{ }^{\mathbf{c}} \\
\text { (aromatic) }\end{array}$ \\
\hline $\mathrm{H}_{2} \mathrm{O}$ & - & 512 & 0.36 & $0 \%$ & $0 \%$ & $22 \%$ & $28 \%$ & $31 \%$ & $19 \%$ \\
\hline Methanol & 2 & 471 & 0.38 & $0 \%$ & $0 \%$ & $22 \%$ & $28 \%$ & $31 \%$ & $19 \%$ \\
\hline $\begin{array}{l}\text { Formaldehyde dimethyl } \\
\text { acetal }\end{array}$ & 1.33 & 62 & 0.34 & $0 \%$ & $0 \%$ & $22 \%$ & $25 \%$ & $28 \%$ & $25 \%$ \\
\hline Formic acid & -2 & 496 & 0.38 & $85 \%$ & $2 \%$ & $22 \%$ & $28 \%$ & $32 \%$ & $18 \%$ \\
\hline Ethanol & 2 & 487 & 0.36 & $0 \%$ & $0 \%$ & $24 \%$ & $27 \%$ & $31 \%$ & $18 \%$ \\
\hline Ethyleneglycol & 1 & 131 & 0.31 & $4 \%$ & $0 \%$ & $23 \%$ & $24 \%$ & $25 \%$ & $28 \%$ \\
\hline Acetaldehyde & 1 & 72 & 0.29 & $7 \%$ & $0 \%$ & $26 \%$ & $23 \%$ & $22 \%$ & $29 \%$ \\
\hline Acetic acid & 0 & 91 & 0.26 & $5 \%$ & $3 \%$ & $21 \%$ & $20 \%$ & $23 \%$ & $36 \%$ \\
\hline $\begin{array}{l}\text { Glycolaldehyde dimethyl } \\
\text { acetal }\end{array}$ & 1 & 40 & 0.31 & $43 \%$ & $3 \%$ & $23 \%$ & $26 \%$ & $28 \%$ & $23 \%$ \\
\hline Methyl glycolate & 0 & 86 & 0.34 & $91 \%$ & $0 \%$ & $23 \%$ & $25 \%$ & $26 \%$ & $26 \%$ \\
\hline 2-Propanol & 2 & 578 & 0.38 & $0 \%$ & $0 \%$ & $21 \%$ & $28 \%$ & $32 \%$ & $19 \%$ \\
\hline 1,2-Propanediol & 1.33 & 190 & 0.32 & $1 \%$ & $0 \%$ & $21 \%$ & $25 \%$ & $29 \%$ & $25 \%$ \\
\hline 1,3-Propanediol & 1.33 & 96 & 0.33 & $1 \%$ & $0 \%$ & $22 \%$ & $25 \%$ & $28 \%$ & $25 \%$ \\
\hline Glycerol & 0.67 & 44 & 0.33 & $8 \%$ & $0 \%$ & $24 \%$ & $23 \%$ & $25 \%$ & $28 \%$ \\
\hline Acetone $^{\mathrm{d}}$ & 1.33 & 271 & 0.29 & $0 \%$ & $1 \%$ & $22 \%$ & $24 \%$ & $26 \%$ & $27 \%$ \\
\hline Propionaldehyde & 1.33 & 138 & 0.31 & $3 \%$ & $0 \%$ & $22 \%$ & $24 \%$ & $26 \%$ & $28 \%$ \\
\hline Propionic acid & 0.67 & 109 & 0.30 & $26 \%$ & $4 \%$ & $22 \%$ & $24 \%$ & $25 \%$ & $29 \%$ \\
\hline Methyl lactate & 0.5 & 189 & 0.33 & $93 \%$ & $0 \%$ & $21 \%$ & $25 \%$ & $28 \%$ & $26 \%$ \\
\hline Methyl acrylate & 0.5 & 27 & 0.27 & $26 \%$ & $10 \%$ & $24 \%$ & $22 \%$ & $25 \%$ & $29 \%$ \\
\hline 1-Butanol & 2 & 679 & 0.39 & $0 \%$ & $0 \%$ & $20 \%$ & $27 \%$ & $32 \%$ & $21 \%$ \\
\hline 1,4-Butanediol & 1.5 & 139 & 0.33 & $0 \%$ & $0 \%$ & $22 \%$ & $25 \%$ & $27 \%$ & $26 \%$ \\
\hline 1,3-Butanediol & 1.5 & 120 & 0.33 & $0 \%$ & $0 \%$ & $23 \%$ & $26 \%$ & $27 \%$ & $24 \%$ \\
\hline 1,2-Butanediol & 1.5 & 166 & 0.33 & n.a. & n.a. & $22 \%$ & $26 \%$ & $28 \%$ & $24 \%$ \\
\hline 2,3 -Butanediol ${ }^{\mathrm{d}}$ & 1.5 & 320 & 0.31 & $0 \%$ & $0 \%$ & $22 \%$ & $25 \%$ & $29 \%$ & $24 \%$ \\
\hline Butyraldehyde & 1.5 & 146 & 0.34 & $5 \%$ & $0 \%$ & $22 \%$ & $25 \%$ & $27 \%$ & $26 \%$ \\
\hline Butanone $\mathrm{d}^{\mathrm{d}}$ & 1.5 & 327 & 0.27 & $0 \%$ & $0 \%$ & $23 \%$ & $25 \%$ & $26 \%$ & $25 \%$ \\
\hline Butyric acid & 1 & 219 & 0.35 & $62 \%$ & $0 \%$ & $21 \%$ & $25 \%$ & $30 \%$ & $24 \%$ \\
\hline 1,5-Pentanediol & 1.6 & 299 & 0.34 & $0 \%$ & $0 \%$ & $22 \%$ & $25 \%$ & $28 \%$ & $25 \%$ \\
\hline Levulinic acid & 0.4 & 37 & 0.29 & $90 \%$ & $0 \%$ & $24 \%$ & $25 \%$ & $25 \%$ & $26 \%$ \\
\hline$\gamma$-Valerolactone & 0.8 & 82 & 0.33 & $78 \%$ & $7 \%$ & $22 \%$ & $26 \%$ & $28 \%$ & $24 \%$ \\
\hline 2-methyl-tetrahydrofuran & 1.6 & 255 & 0.36 & $0 \%$ & $0 \%$ & $20 \%$ & $25 \%$ & $29 \%$ & $26 \%$ \\
\hline Toluene & 1.14 & 412 & 0.33 & $0 \%$ & $0 \%$ & $19 \%$ & $20 \%$ & $21 \%$ & $40 \%$ \\
\hline Anisole & 0.86 & 10 & na. & $0 \%$ & $0 \%$ & $26 \%$ & $21 \%$ & $21 \%$ & $32 \%$ \\
\hline 1,2-dimethoxybenzene & 0.75 & 9 & na. & $0 \%$ & $0 \%$ & $28 \%$ & $20 \%$ & $26 \%$ & $26 \%$ \\
\hline
\end{tabular}

${ }^{\mathrm{a}} \mathrm{g}_{\text {feed }} / \mathrm{g}_{\text {zeolite, }}{ }^{\mathrm{b}} \mathrm{mol} / \mathrm{mol}_{\text {additive, }}{ }^{\text {cinitial, }}{ }^{\mathrm{d}}$ breakthrough of additive before DME/methanol

Table 1. Conversion capacity, initial selectivity, $\mathrm{C}_{4}-\mathrm{HTI}$, and $\mathrm{CO} / \mathrm{CO}_{2}$ production from conversion of various oxygenates as $10 \%$ solutions in methanol $\left(\mathrm{T}=370{ }^{\circ} \mathrm{C}, \mathrm{P}=1 \mathrm{bar}, 300 \mathrm{mg}\right.$ $\mathrm{H}-\mathrm{ZSM}-5$, WHSV $=8 \mathrm{~h}^{-1}$ ) 


\begin{tabular}{|c|c|c|c|c|c|c|c|c|c|}
\hline Additive & wt $\%$ & $\begin{array}{l}\text { Eff. } H / C \\
\text { of feed }^{a}\end{array}$ & $\mathrm{C}_{4}-\mathrm{HTI}^{\mathrm{b}}$ & $\mathrm{CO}^{\mathrm{c}}$ & $\mathrm{CO}_{2}{ }^{\mathrm{c}}$ & $\mathrm{C}_{1-3}^{\mathrm{b}}$ & $\mathrm{C}_{4}{ }^{\mathrm{b}}$ & $\begin{array}{l}\mathbf{C}_{\mathbf{5}+}^{\mathbf{b}} \\
\text { (aliphatic) }\end{array}$ & $\begin{array}{l}\mathbf{C}_{6-10} \mathbf{b}^{\prime} \\
\text { (aromatic) }\end{array}$ \\
\hline Methanol & - & 2 & 0.38 & $0 \%$ & $0 \%$ & $22 \%$ & $28 \%$ & $31 \%$ & $19 \%$ \\
\hline Acetic acid & $2.5 \%$ & 1.95 & 0.34 & $0 \%$ & $0 \%$ & $24 \%$ & $26 \%$ & $28 \%$ & $22 \%$ \\
\hline Acetic acid & $5 \%$ & 1.89 & 0.31 & $4 \%$ & $4 \%$ & $24 \%$ & $24 \%$ & $26 \%$ & $26 \%$ \\
\hline Acetic acid & $10 \%$ & 1.79 & 0.27 & $5 \%$ & $3 \%$ & $21 \%$ & $20 \%$ & $23 \%$ & $36 \%$ \\
\hline Acetic acid & $25 \%$ & 1.48 & 0.19 & $6 \%$ & $9 \%$ & $21 \%$ & $12 \%$ & $13 \%$ & $53 \%$ \\
\hline Glycerol & $1 \%$ & 1.99 & 0.38 & $0 \%$ & $0 \%$ & $22 \%$ & $27 \%$ & $30 \%$ & $21 \%$ \\
\hline Glycerol & $2.5 \%$ & 1.97 & 0.36 & $0 \%$ & $0 \%$ & $23 \%$ & $27 \%$ & $29 \%$ & $21 \%$ \\
\hline Glycerol & $5 \%$ & 1.93 & 0.34 & $10 \%$ & $0 \%$ & $24 \%$ & $26 \%$ & $27 \%$ & $23 \%$ \\
\hline Glycerol & $10 \%$ & 1.86 & 0.30 & $11 \%$ & $0 \%$ & $24 \%$ & $23 \%$ & $25 \%$ & $28 \%$ \\
\hline Glycerol & $25 \%$ & 1.66 & 0.23 & $16 \%$ & $2 \%$ & $23 \%$ & $20 \%$ & $20 \%$ & $37 \%$ \\
\hline Glycerol & $50 \%$ & 1.32 & na. $^{\mathrm{d}}$ & $21 \%$ & $3 \%$ & $24 \%$ & $15 \%$ & $16 \%$ & $45 \%$ \\
\hline Methyl lactate & $2.5 \%$ & 1.95 & 0.39 & $70 \%$ & $0 \%$ & $21 \%$ & $26 \%$ & $30 \%$ & $23 \%$ \\
\hline Methyl lactate & $10 \%$ & 1.82 & 0.33 & $93 \%$ & $0 \%$ & $21 \%$ & $25 \%$ & $28 \%$ & $26 \%$ \\
\hline Methyl lactate & $17.5 \%$ & 1.69 & 0.31 & $>95 \%$ & $1 \%$ & $23 \%$ & $24 \%$ & $26 \%$ & $27 \%$ \\
\hline Methyl lactate & $25 \%$ & 1.56 & 0.27 & $>95 \%$ & $1 \%$ & $23 \%$ & $22 \%$ & $23 \%$ & $32 \%$ \\
\hline Methyl lactate & $50 \%$ & 1.17 & 0.20 & $>95 \%$ & $1 \%$ & $25 \%$ & $17 \%$ & $17 \%$ & $41 \%$ \\
\hline Methyl lactate & $100 \%$ & 0.50 & na. $^{\mathrm{d}}$ & na. $^{\mathrm{d}}$ & na. $^{d}$ & $26 \%$ & $7 \%$ & $6 \%$ & $61 \%$ \\
\hline$\gamma$-Valerolactone & $2.5 \%$ & 1.95 & 0.39 & $76 \%$ & $<2 \%$ & $24 \%$ & $27 \%$ & $28 \%$ & $21 \%$ \\
\hline$\gamma$-Valerolactone & $5 \%$ & 1.91 & 0.38 & $78 \%$ & $6 \%$ & $22 \%$ & $27 \%$ & $29 \%$ & $22 \%$ \\
\hline$\gamma$-Valerolactone & $10 \%$ & 1.82 & 0.32 & $78 \%$ & $7 \%$ & $22 \%$ & $26 \%$ & $28 \%$ & $24 \%$ \\
\hline$\gamma$-Valerolactone & $25 \%$ & 1.58 & 0.27 & $73 \%$ & $9 \%$ & $23 \%$ & $23 \%$ & $25 \%$ & $29 \%$ \\
\hline$\gamma$-Valerolactone & $50 \%$ & 1.26 & 0.24 & $72 \%$ & $11 \%$ & $21 \%$ & $20 \%$ & $19 \%$ & $40 \%$ \\
\hline$\gamma$-Valerolactone & $100 \%$ & 0.80 & na. $^{\mathrm{d}}$ & na. $^{\mathrm{d}}$ & na. $^{\mathrm{d}}$ & $17 \%$ & $16 \%$ & $15 \%$ & $52 \%$ \\
\hline
\end{tabular}

${ }^{a}$ calculated from the dehydrated $\mathrm{H} / \mathrm{C}$ ratios, ${ }^{b}$ initial, ${ }^{c} \mathrm{~mol} / \mathrm{mol}_{\text {additive }}{ }^{\mathrm{d}}$ too rapid catalyst deactivation to obtain data

Table 2. Initial selectivity, $\mathrm{C}_{4}-\mathrm{HTI}$, and $\mathrm{CO} / \mathrm{CO}_{2}$ production from conversion of different concentrations of various oxygenates in methanol $\left(\mathrm{T}=370{ }^{\circ} \mathrm{C}, \mathrm{P}=1\right.$ bar, $300 \mathrm{mg} \mathrm{H}-\mathrm{ZSM}-5$, $\mathrm{WHSV}=8 \mathrm{~h}^{-1}$ ). 


\begin{tabular}{ccc}
\hline $\begin{array}{c}\text { BET surface area } \\
\mathrm{m}^{2} / \mathrm{g}\end{array}$ & $\begin{array}{c}\mathrm{V}_{\text {micro }} \\
\mathrm{cm}^{3} / \mathrm{g}\end{array}$ & $\begin{array}{c}\text { Elemental composition } \\
\mathrm{Si} / \mathrm{Al}\end{array}$ \\
\hline 398 & 0.11 & 37 \\
\hline
\end{tabular}

Table S1. Characterization data for the employed H-ZSM-5 catalyst. BET surface area (multi point) and $\mathrm{V}_{\text {micro }}(\mathrm{T}$-plot) are obtained from physisorption of nitrogen on a Micromeritecs ASAP 2020. The elemental composition is determined by ICP-OES. 


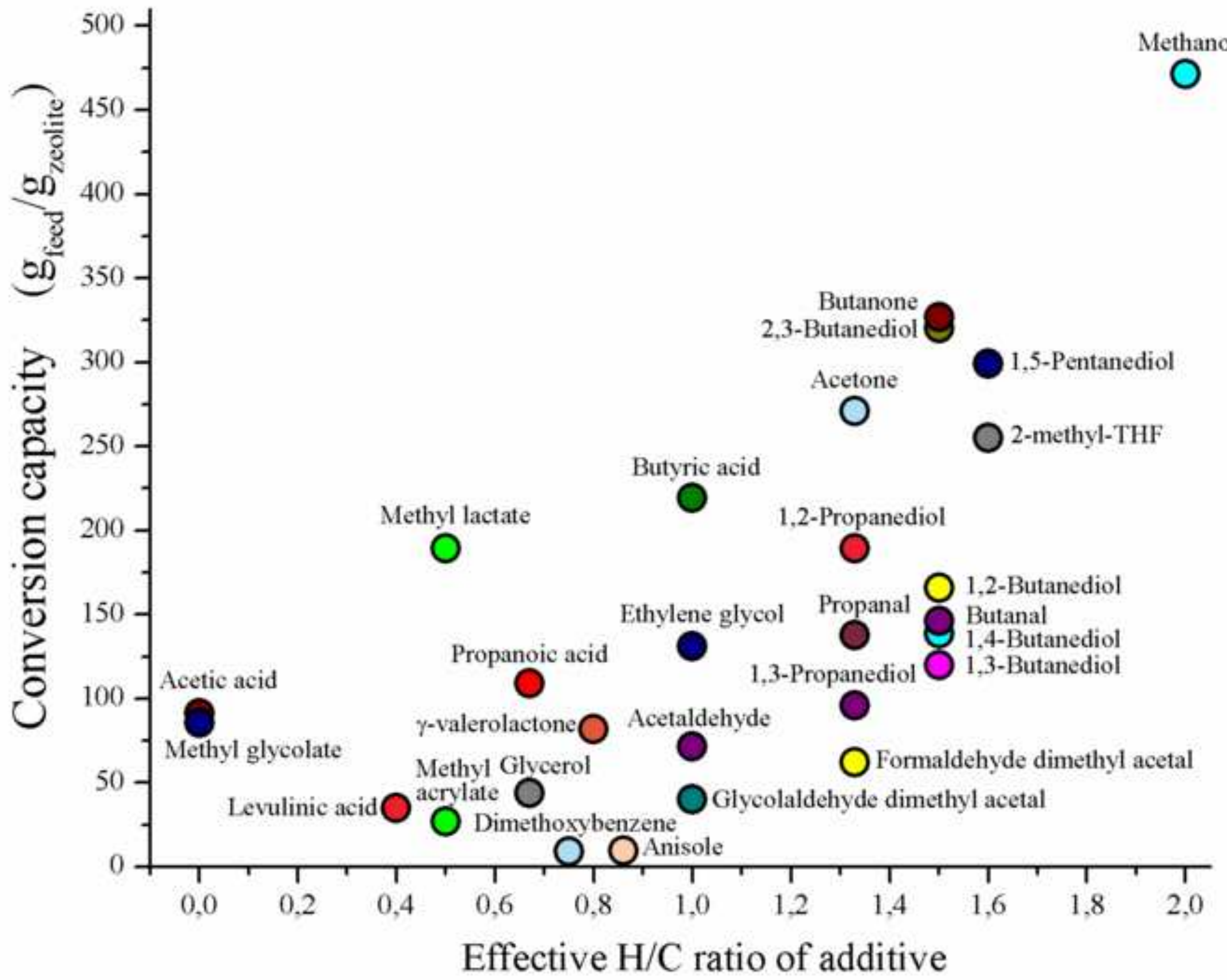

rage 26 or $4 y$ 


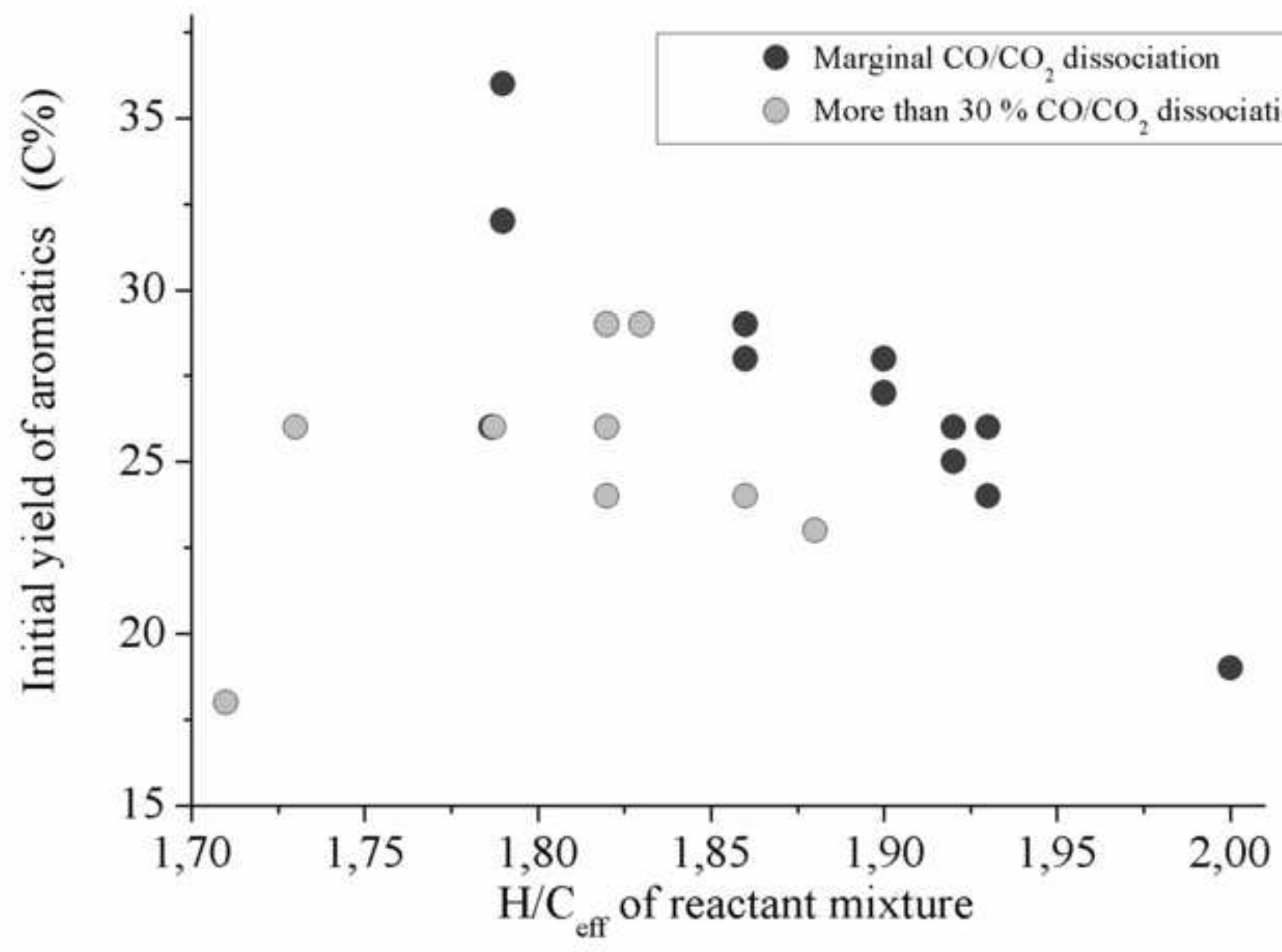




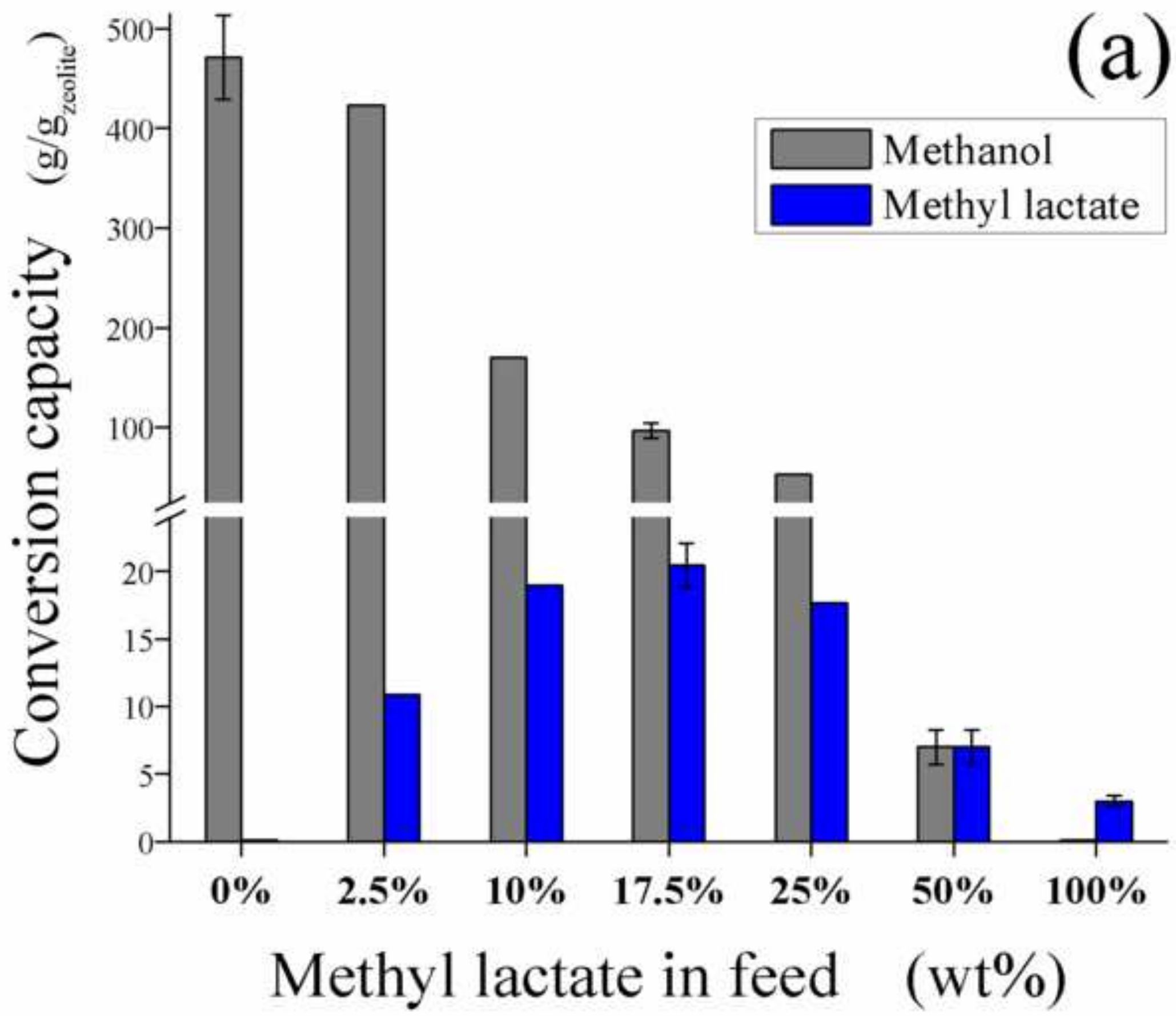




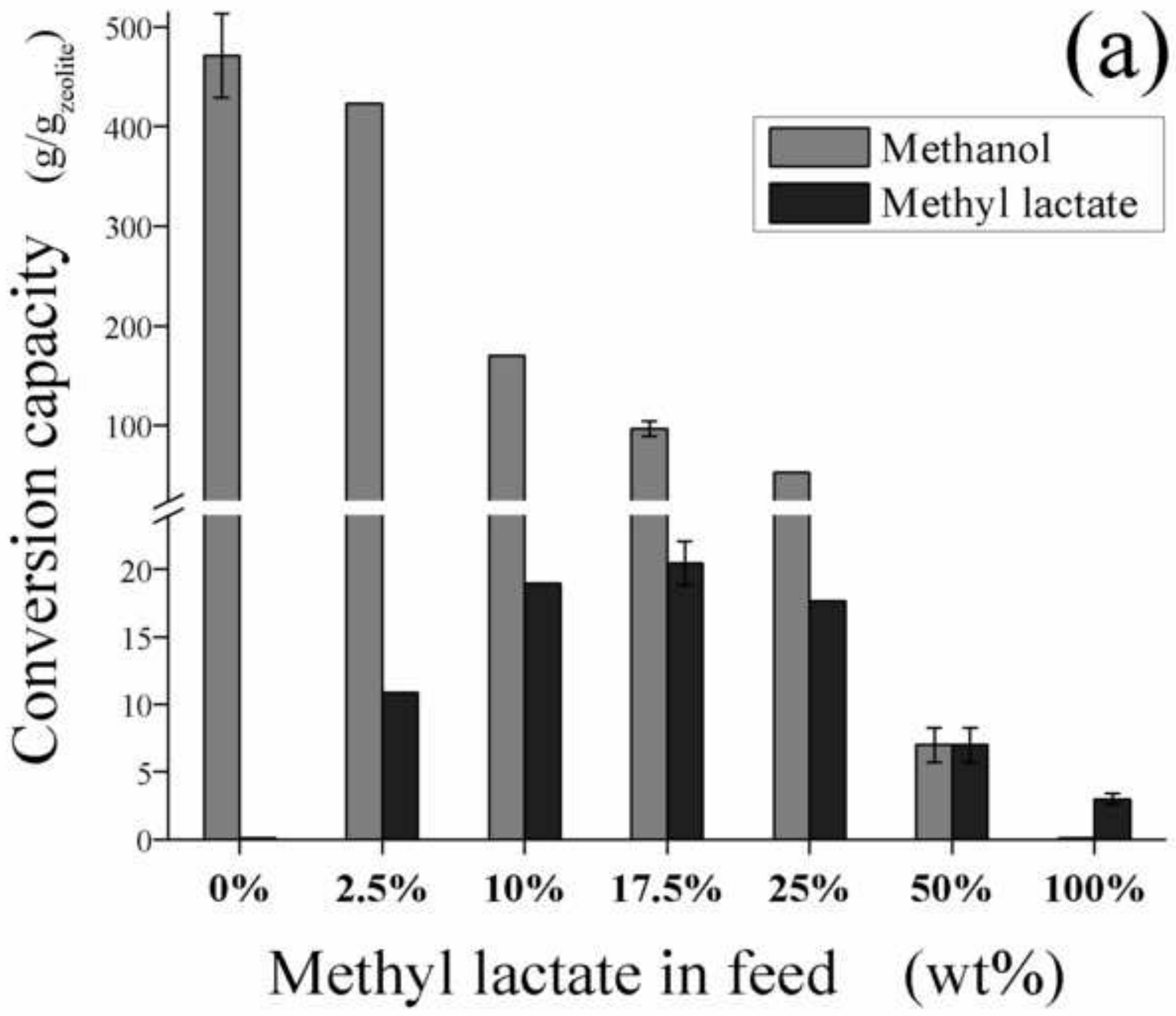

rage $2 y$ or $4 y$ 


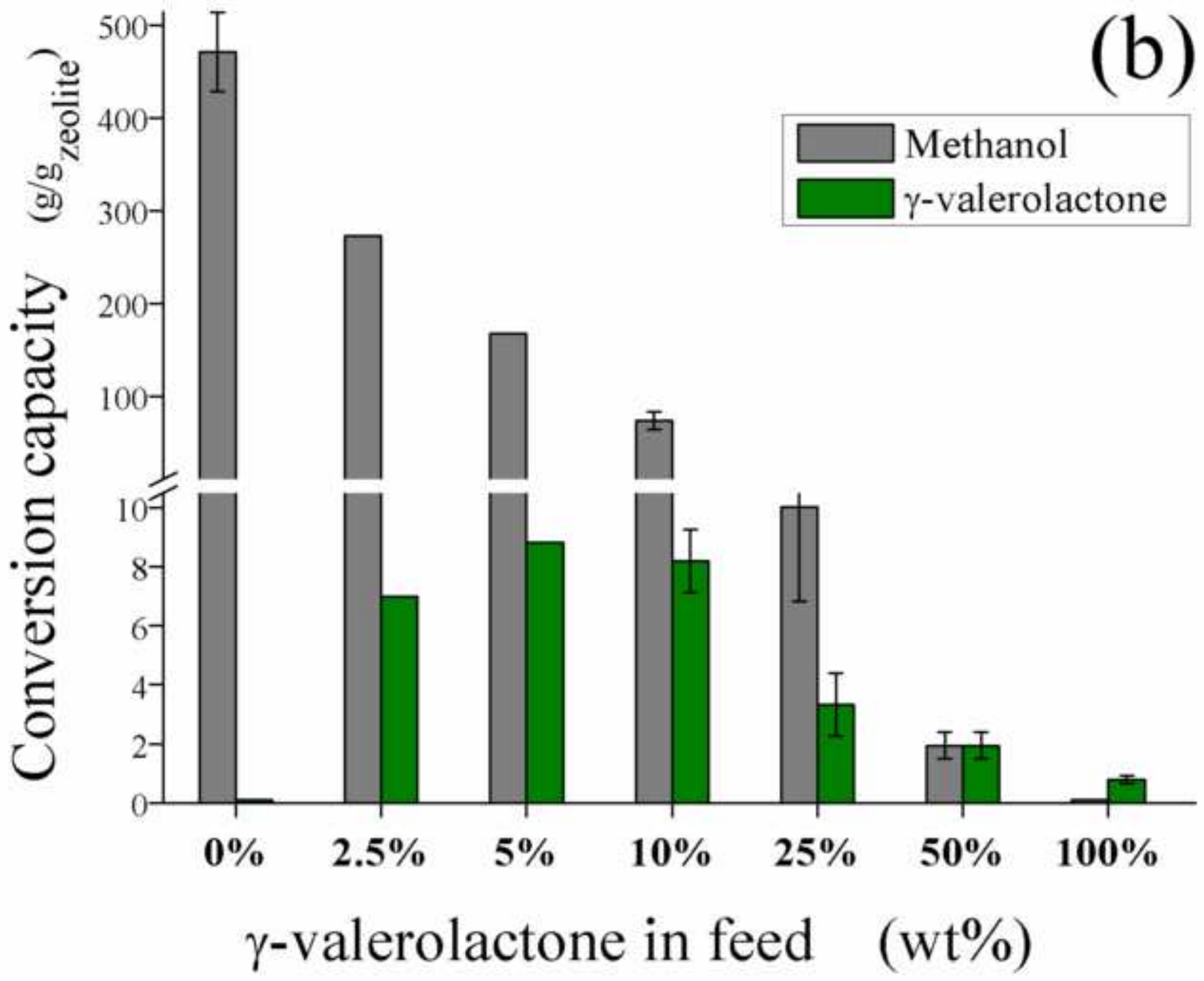

rage 30 ot $4 y$ 


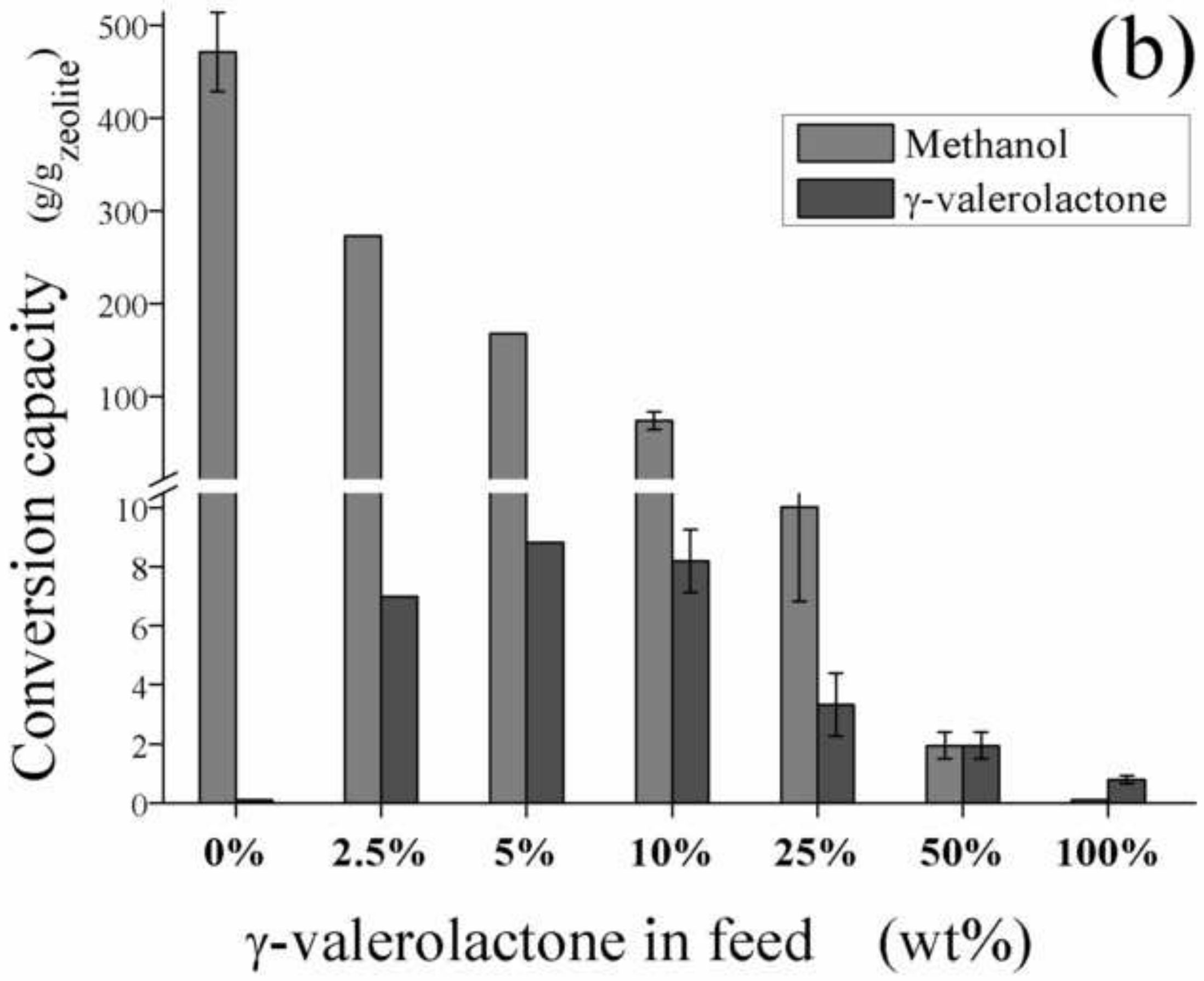

rage 31 or $4 y$ 


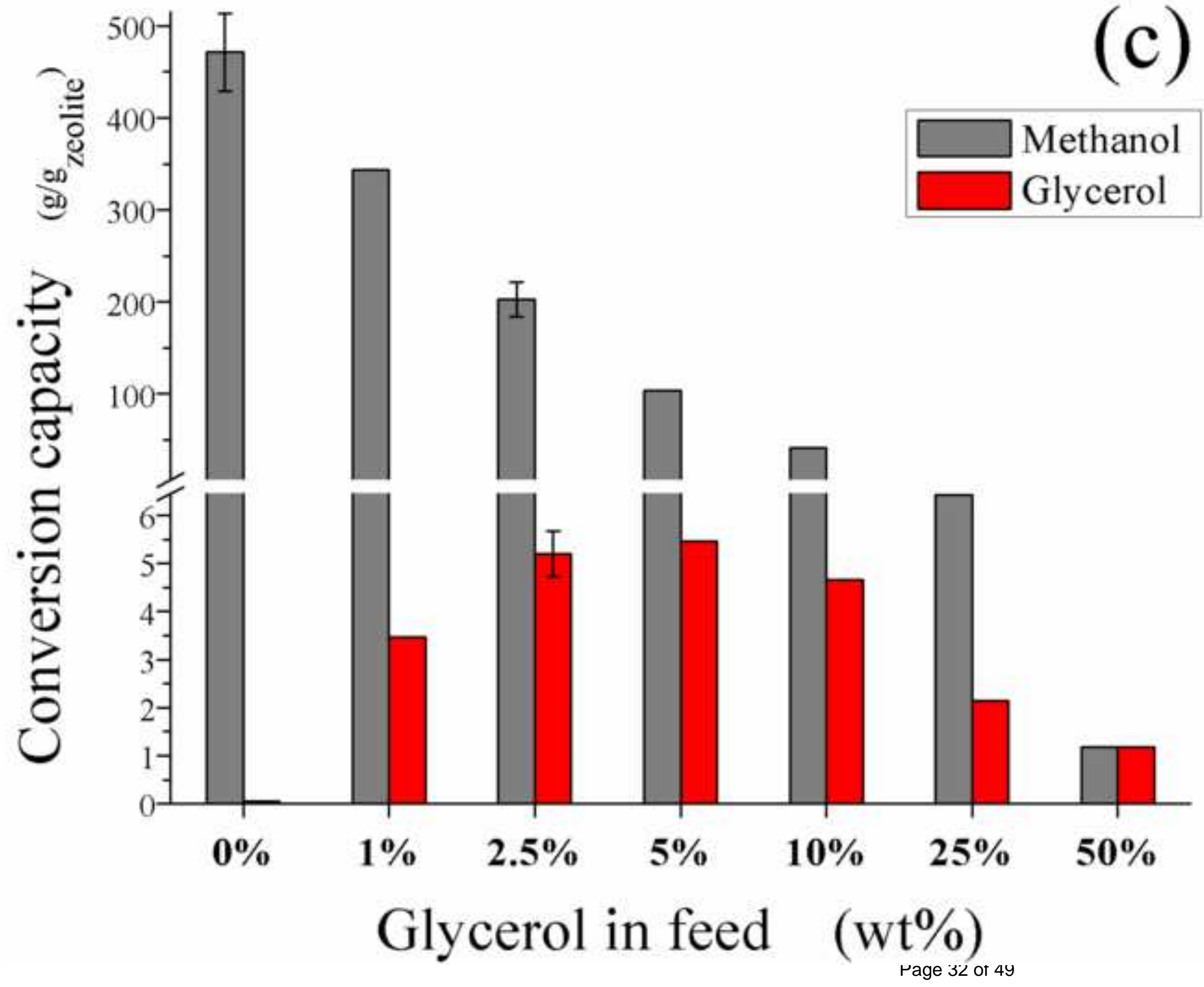




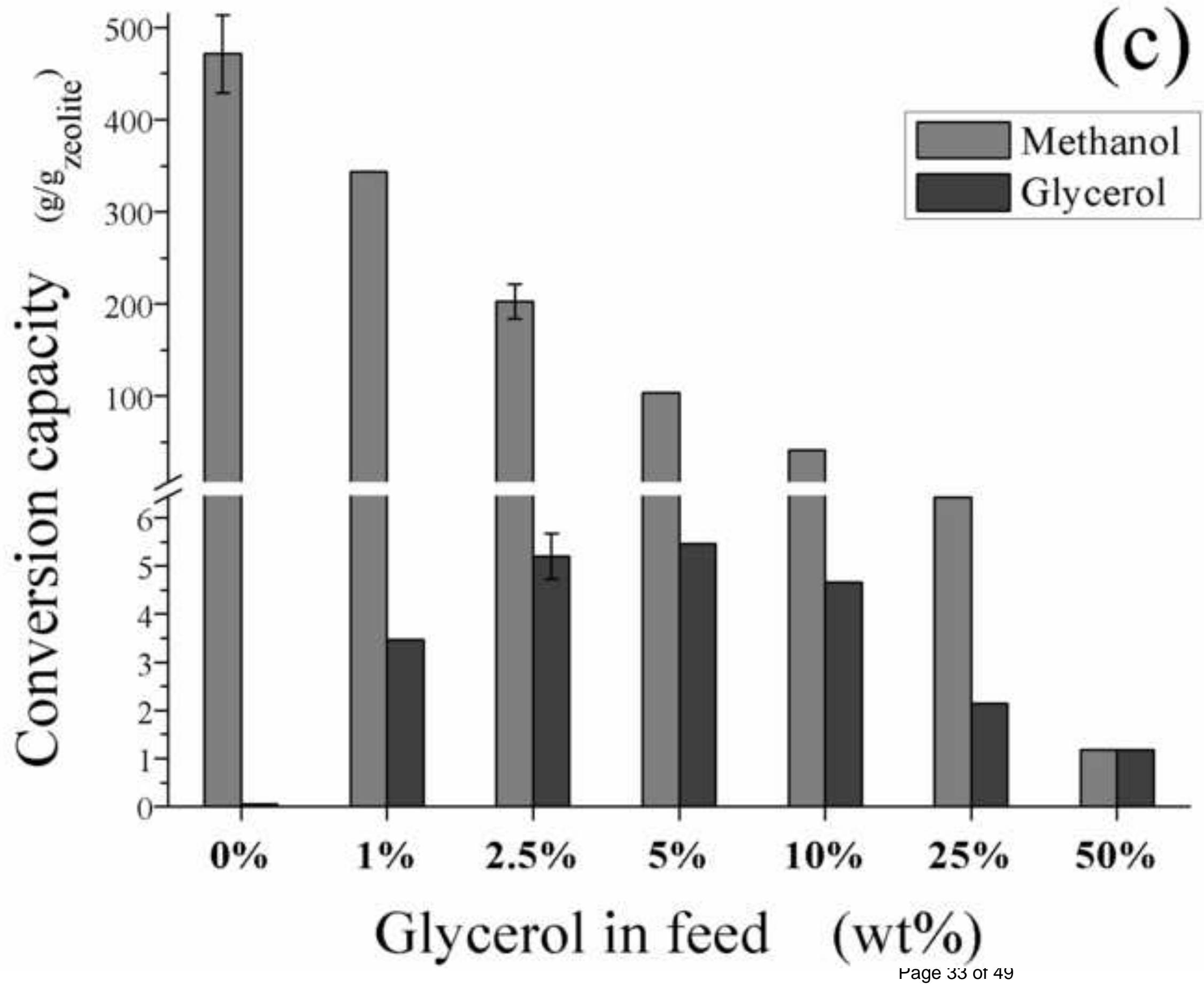




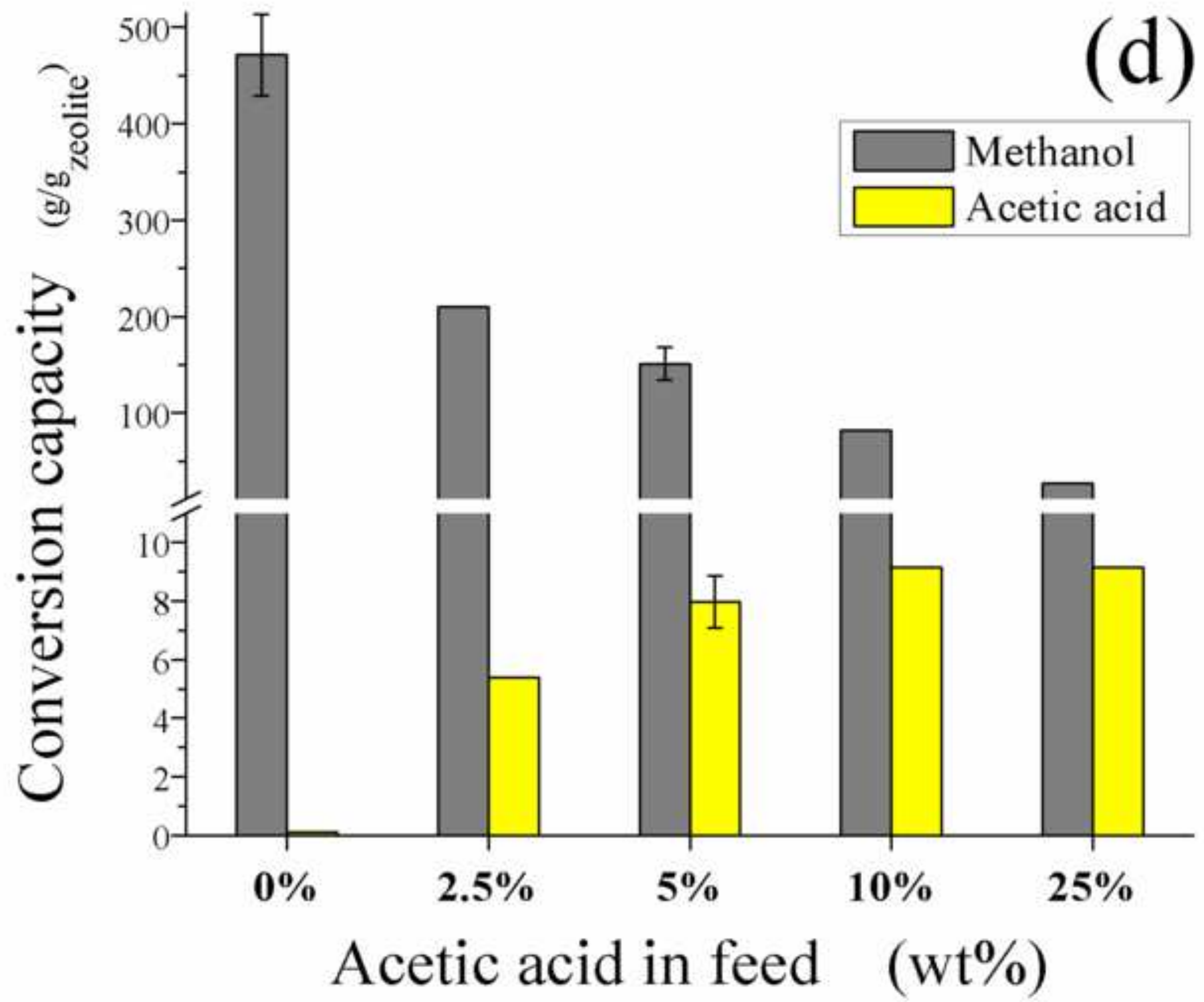




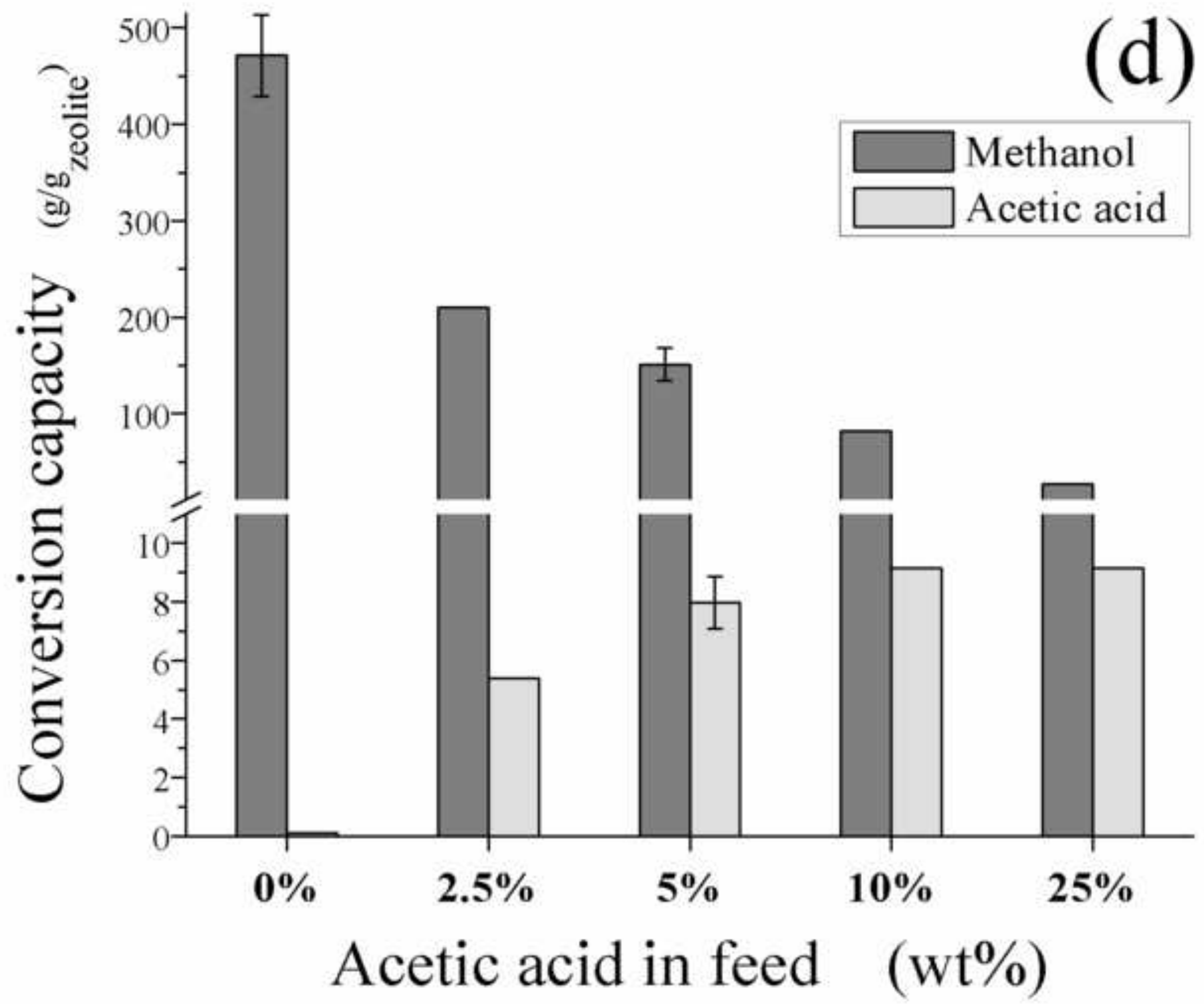




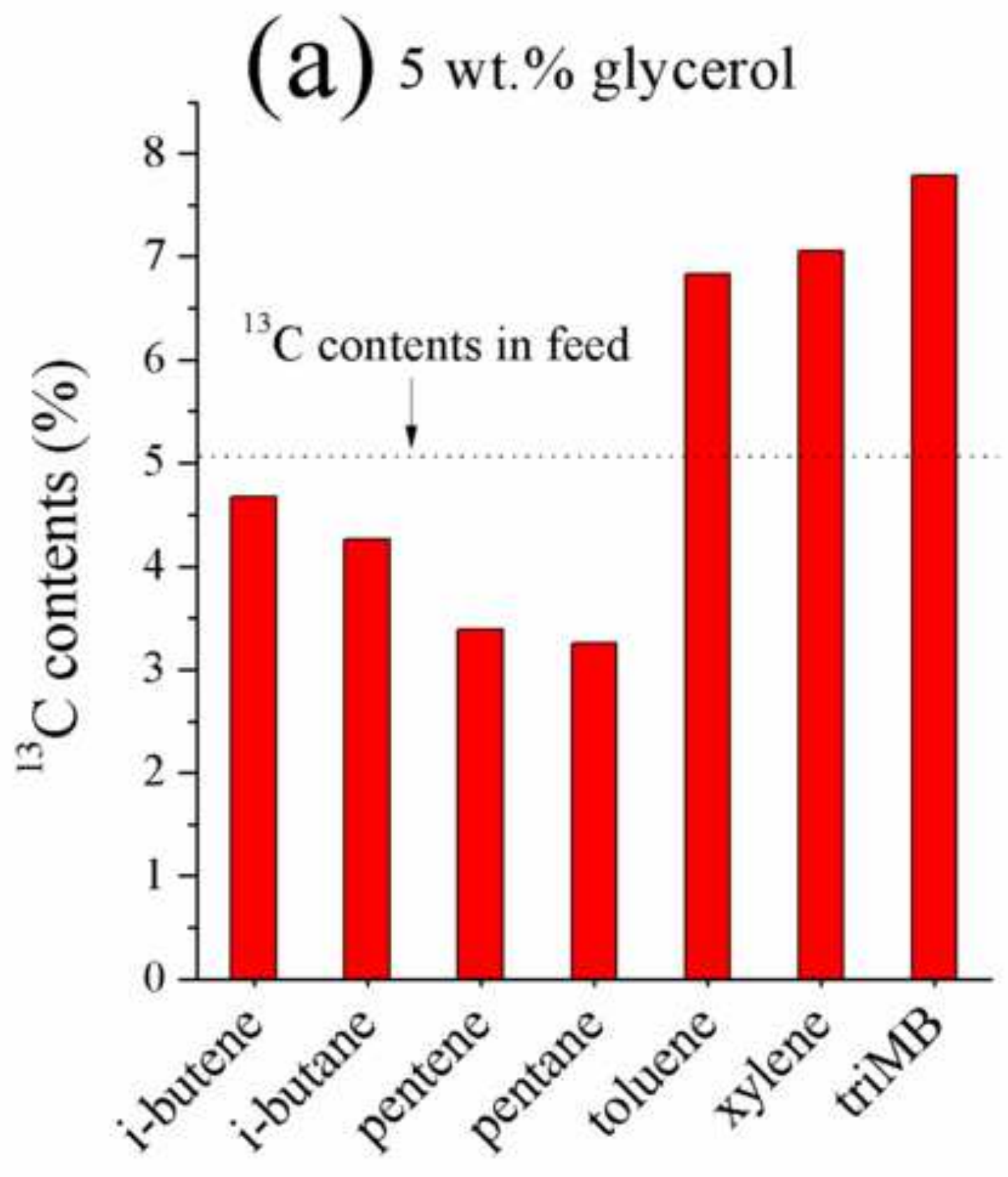




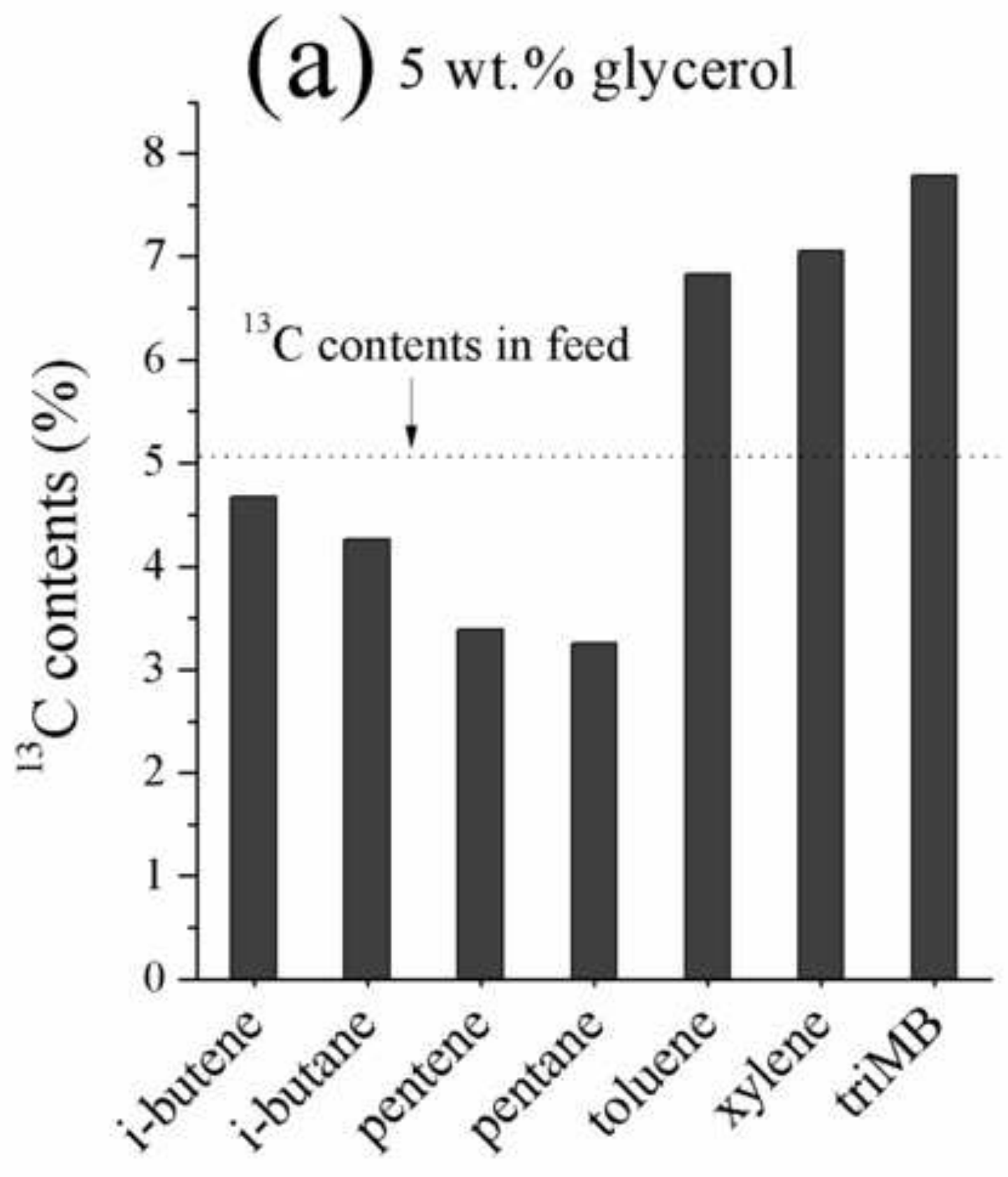




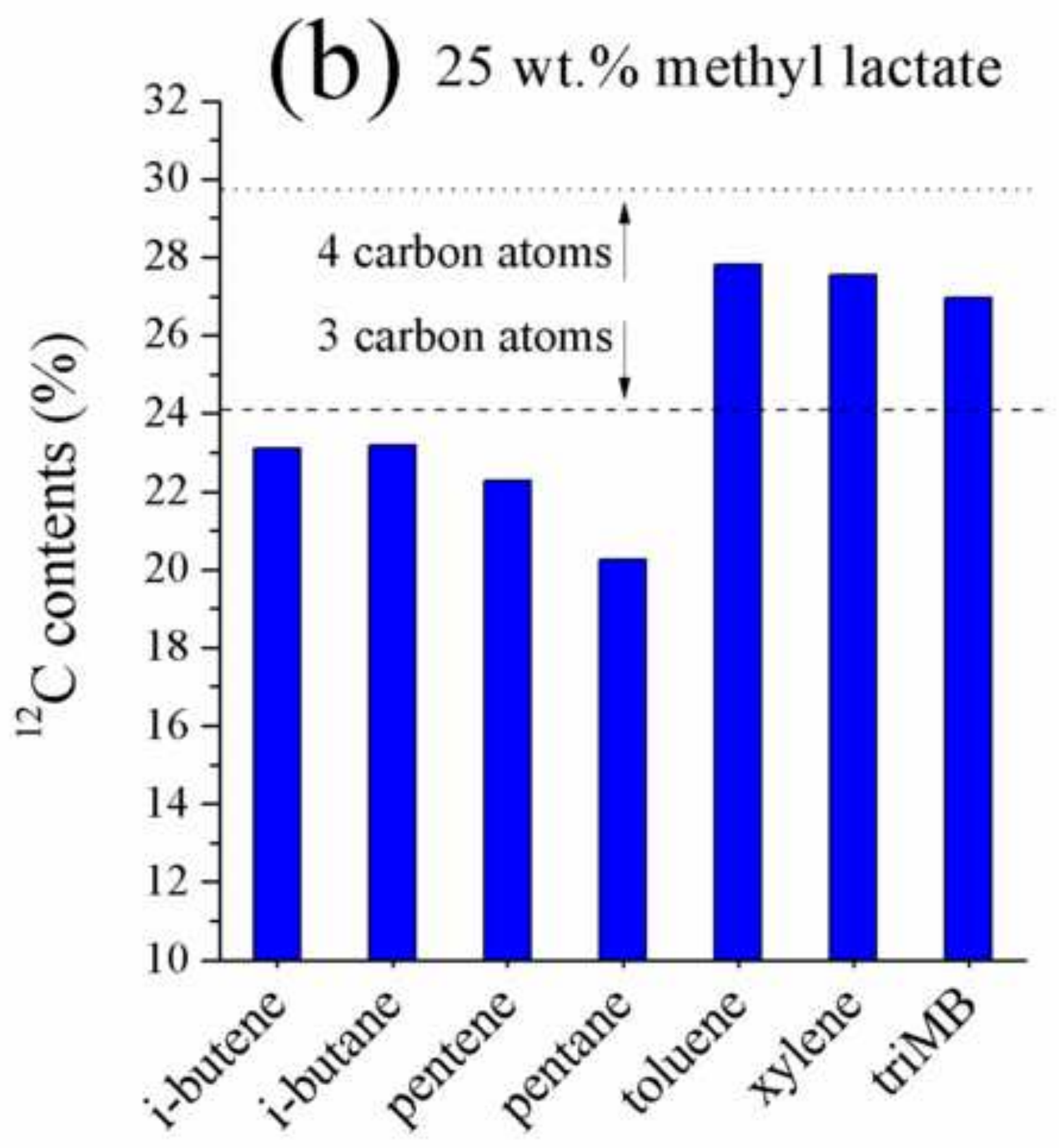




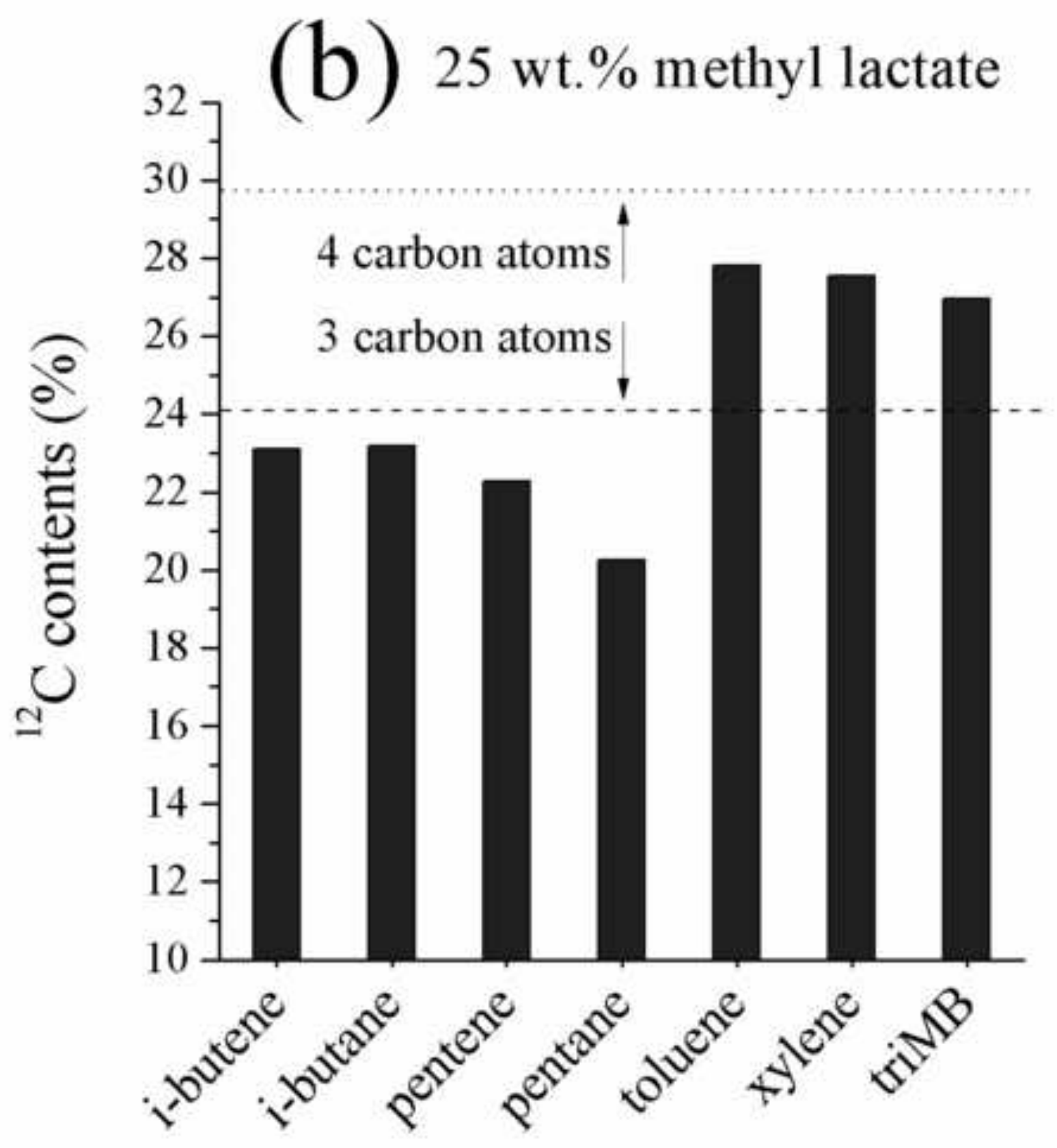




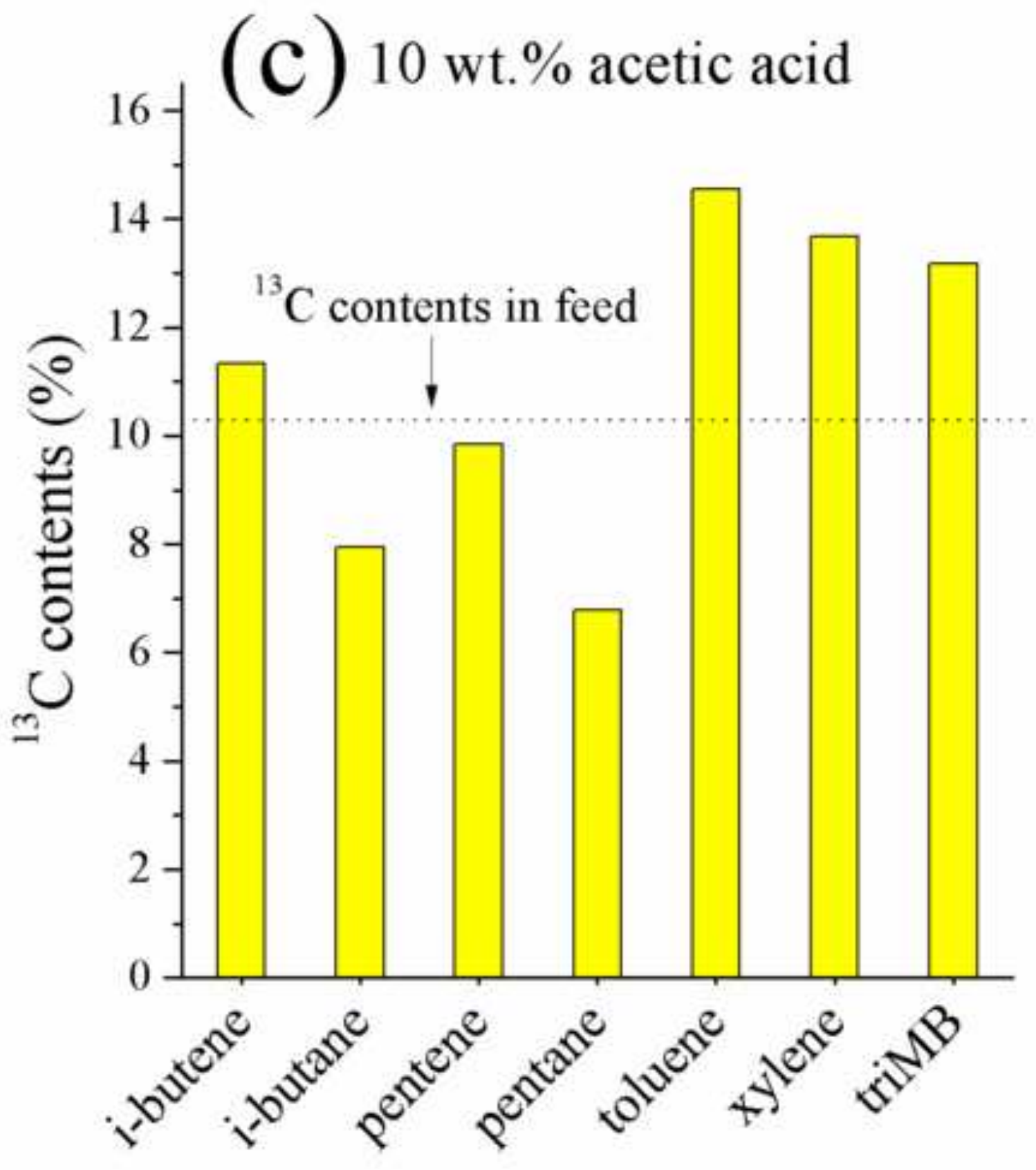




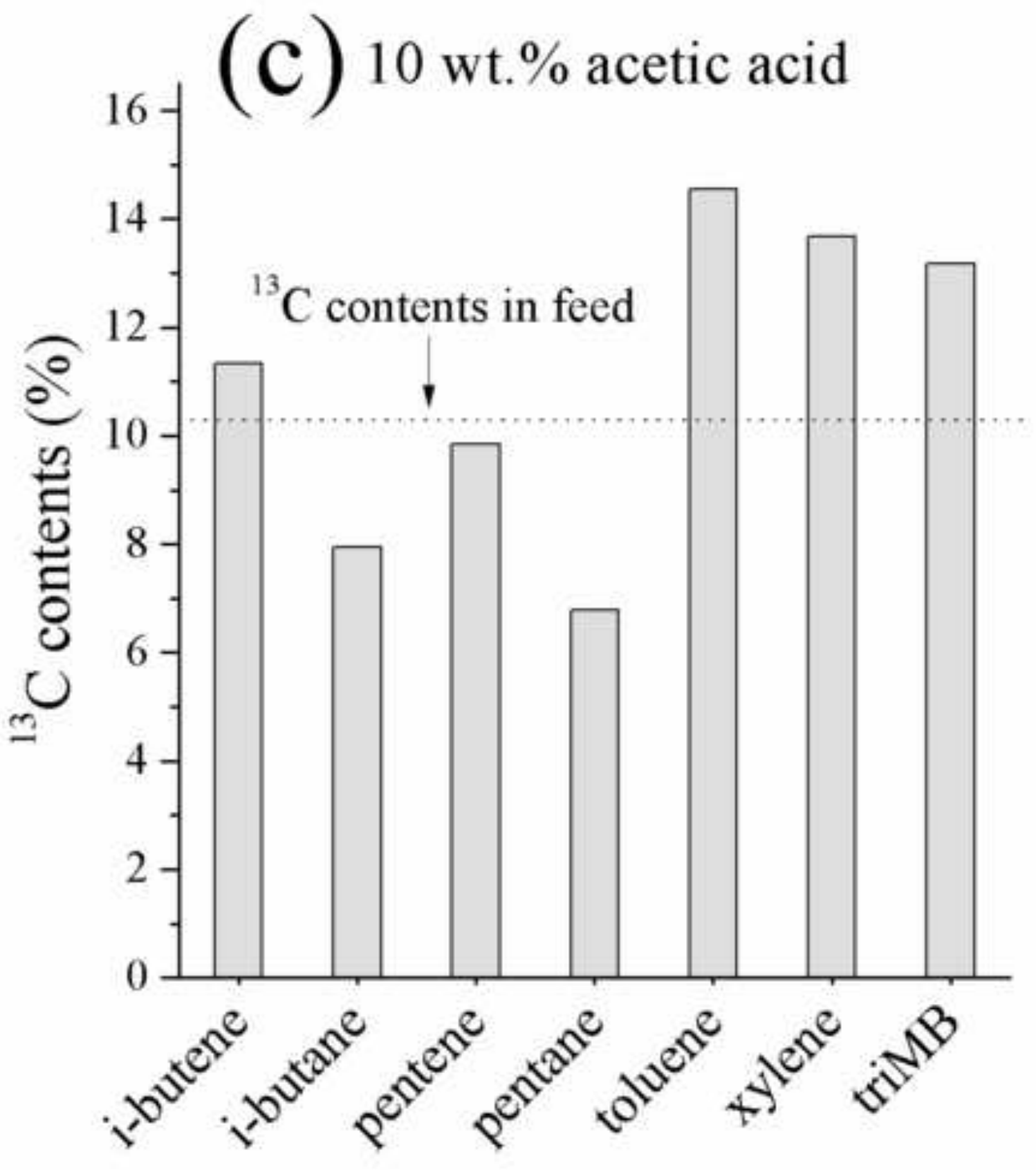




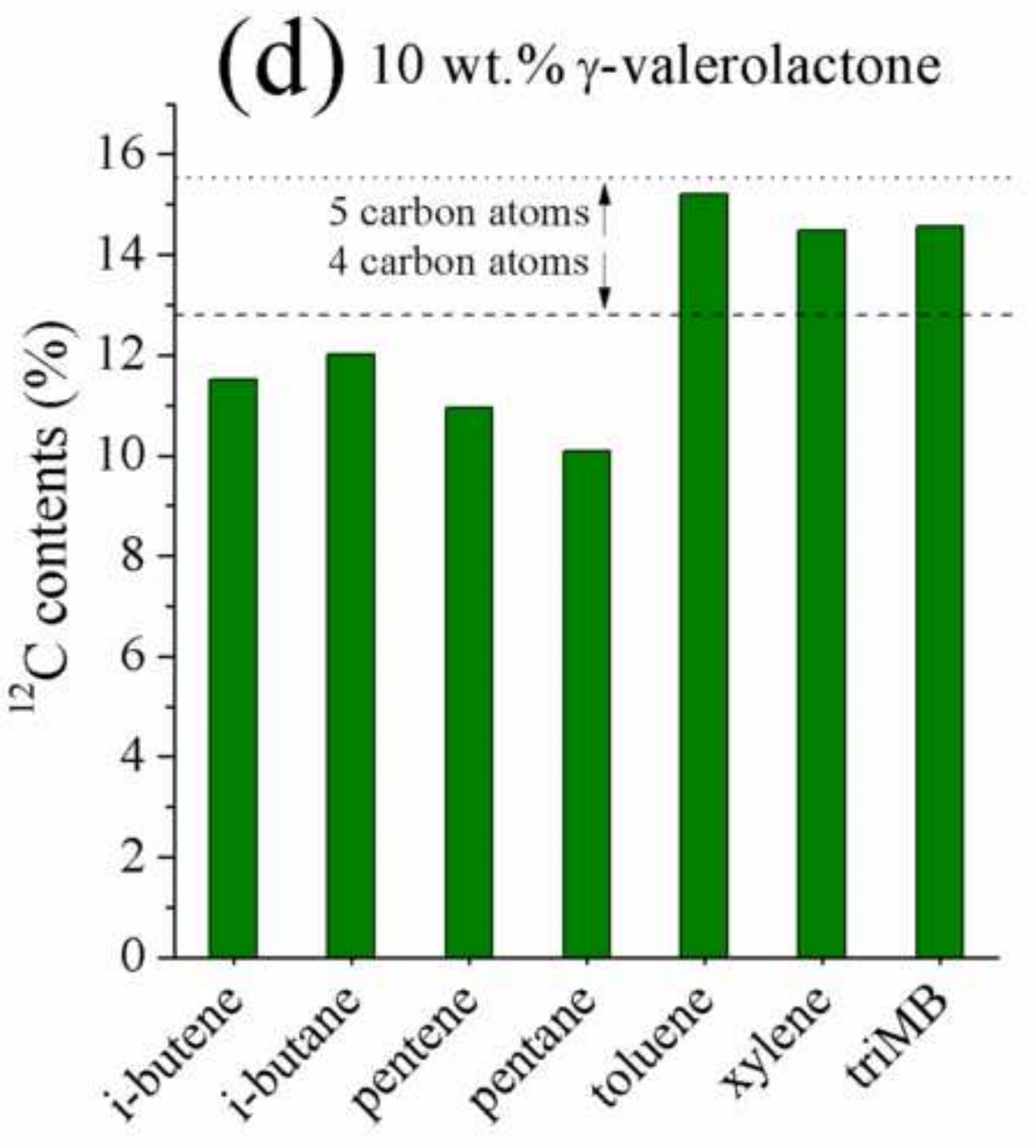




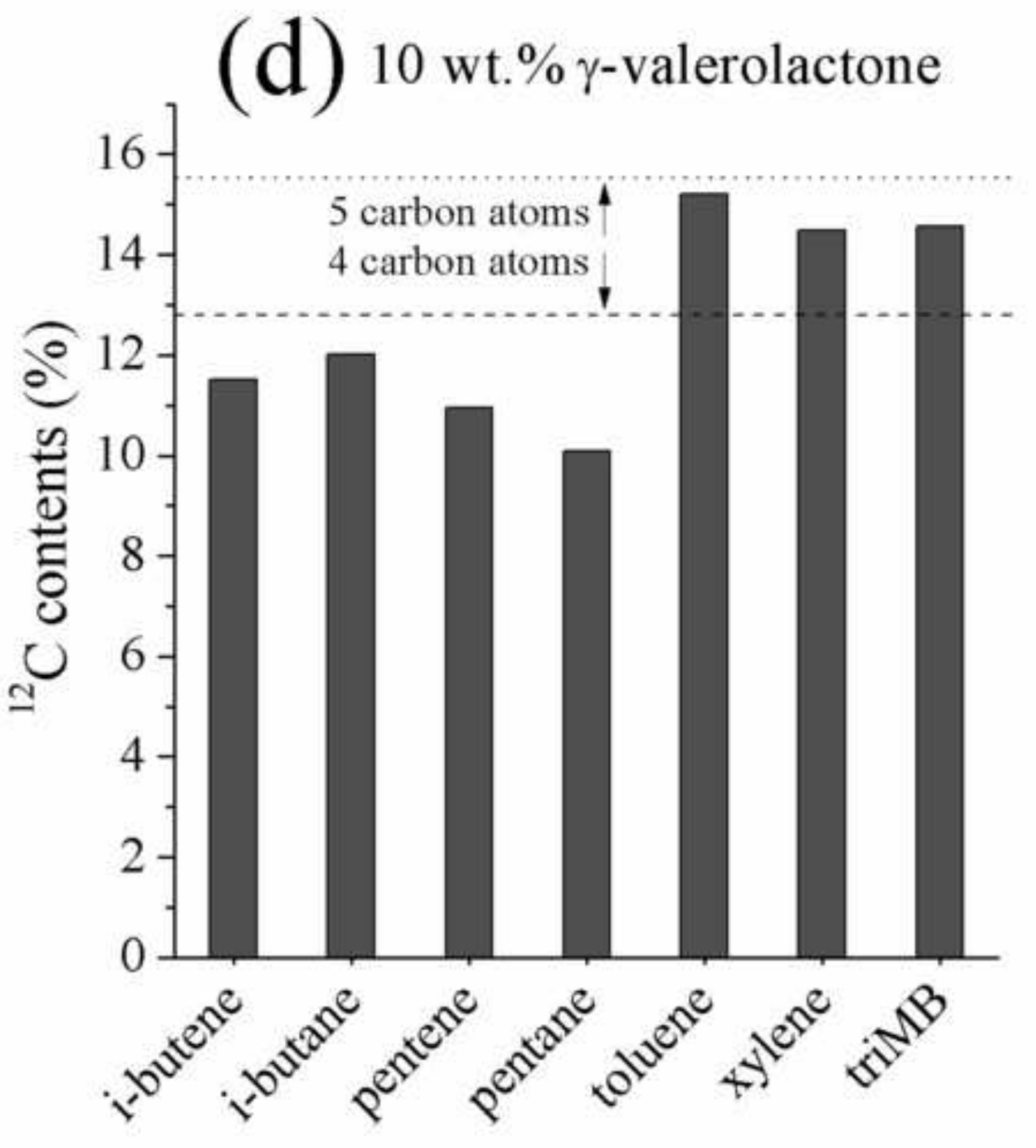




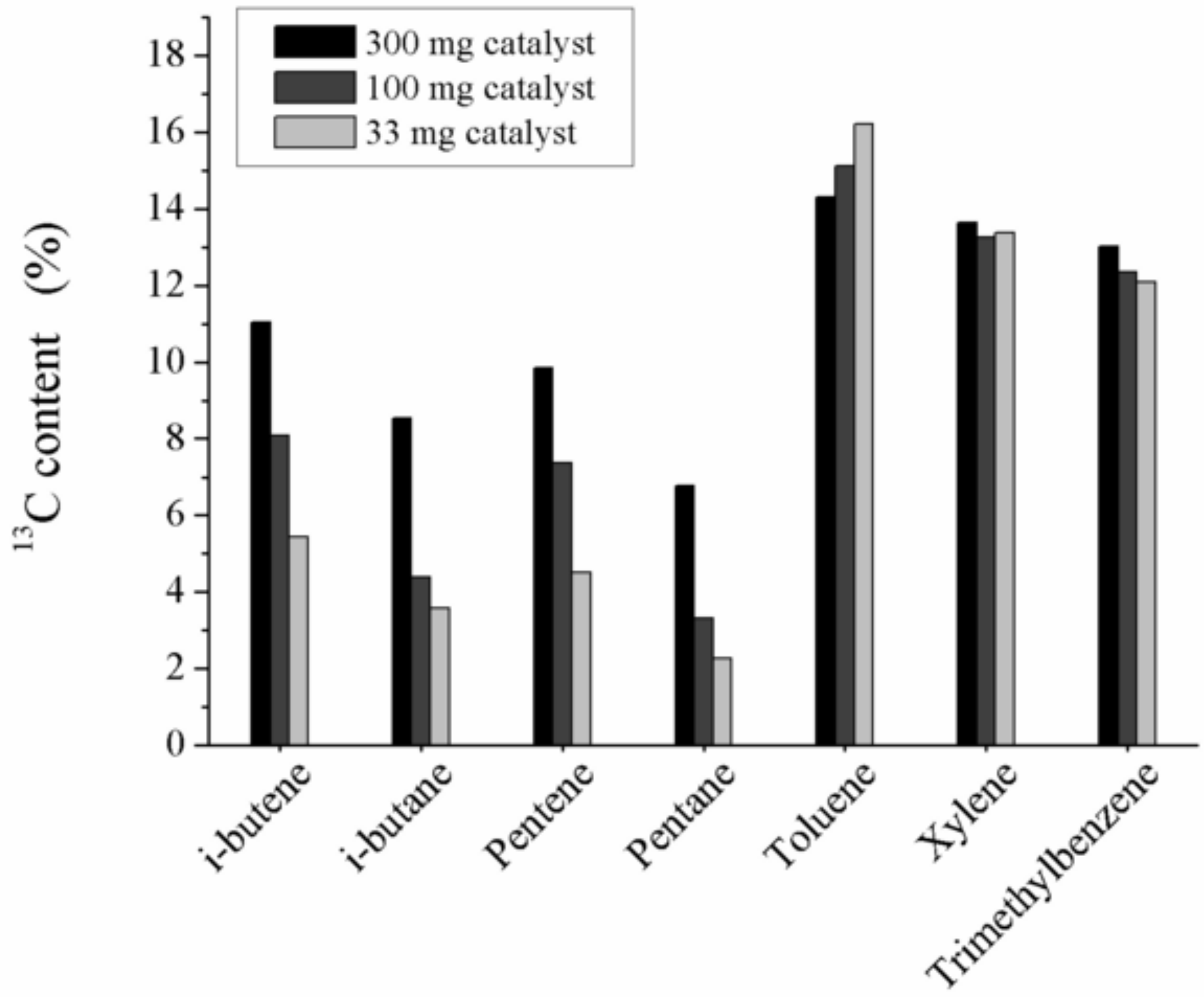

Page 44 of 49 


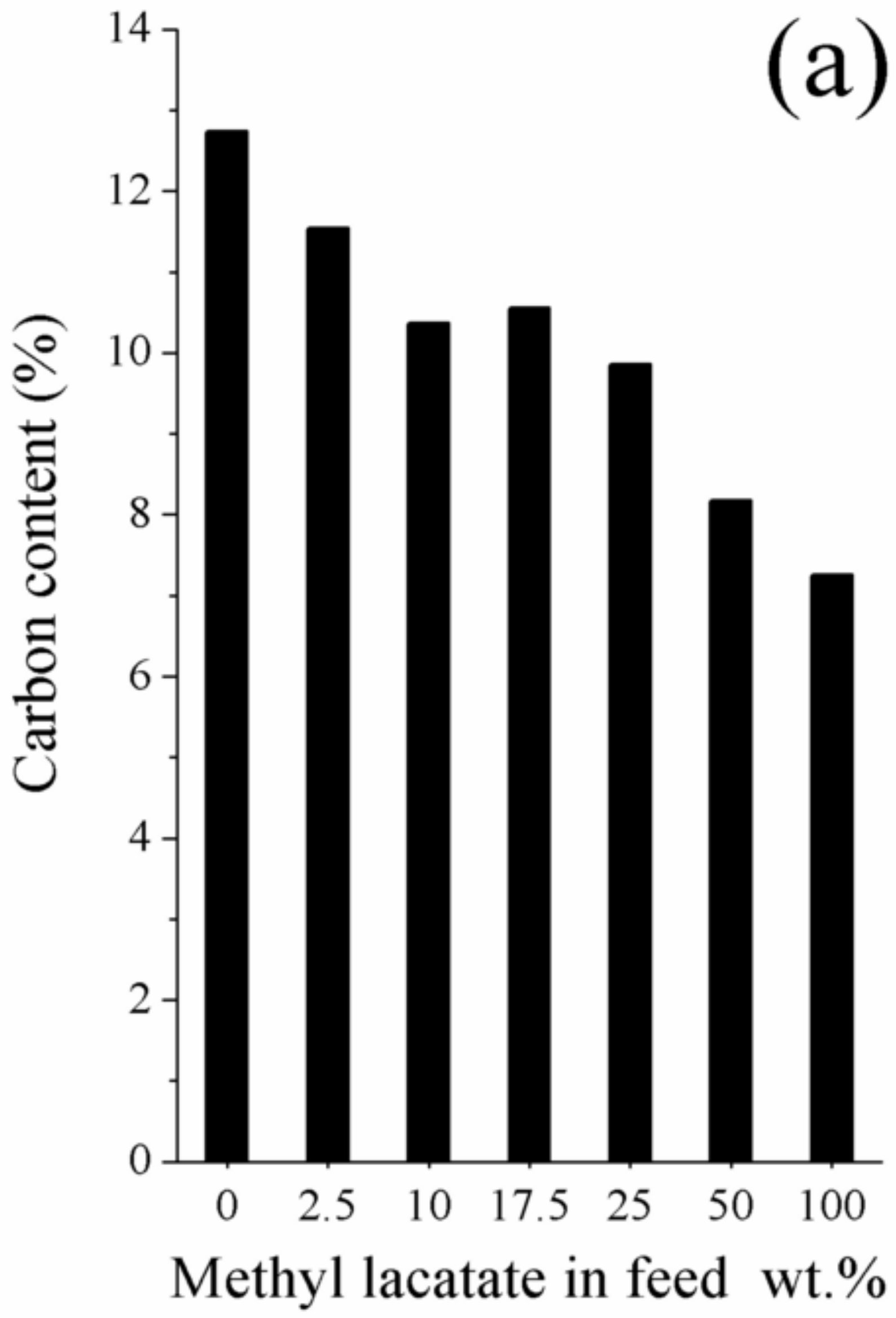




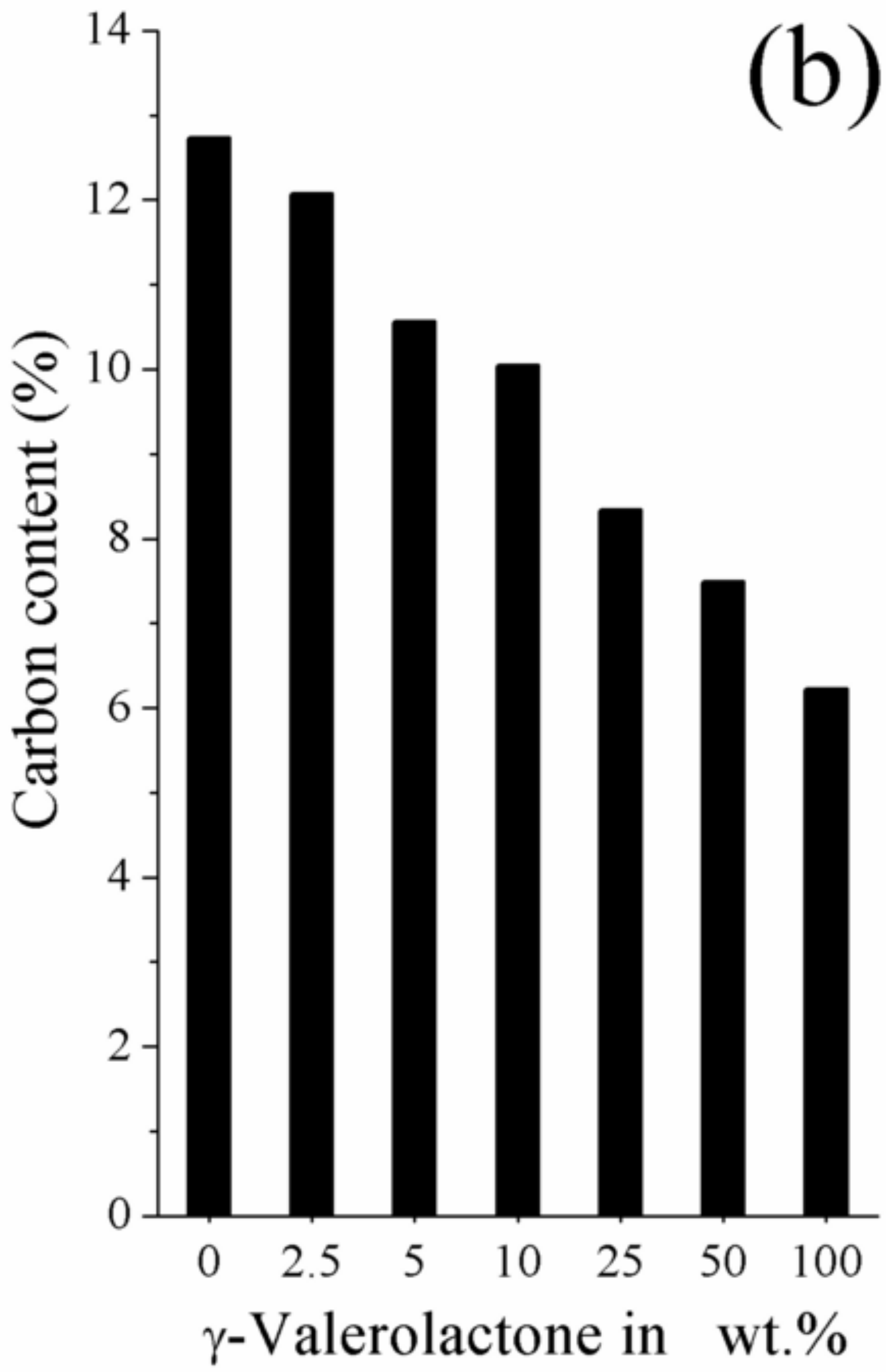




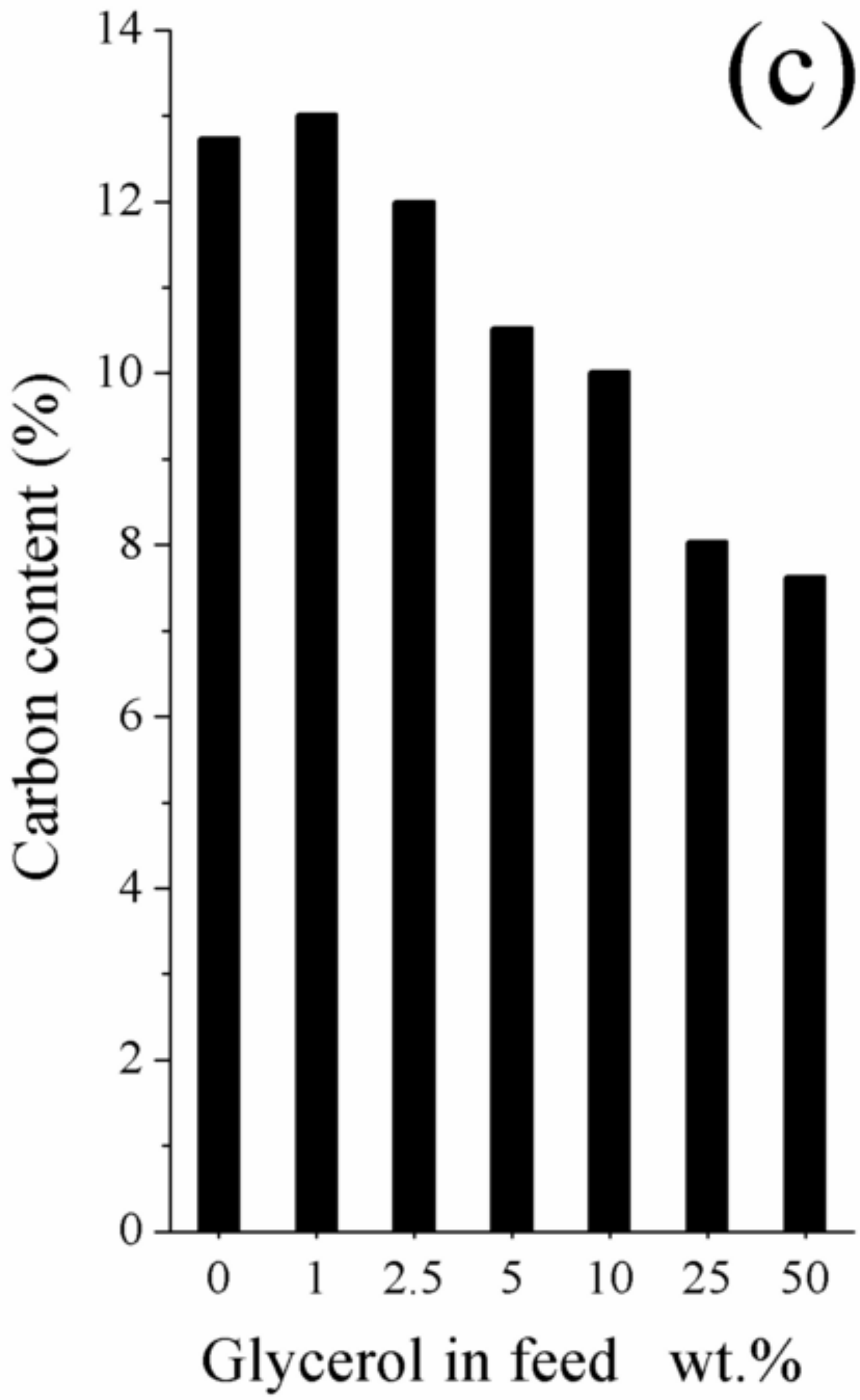


Click here to download high resolution image

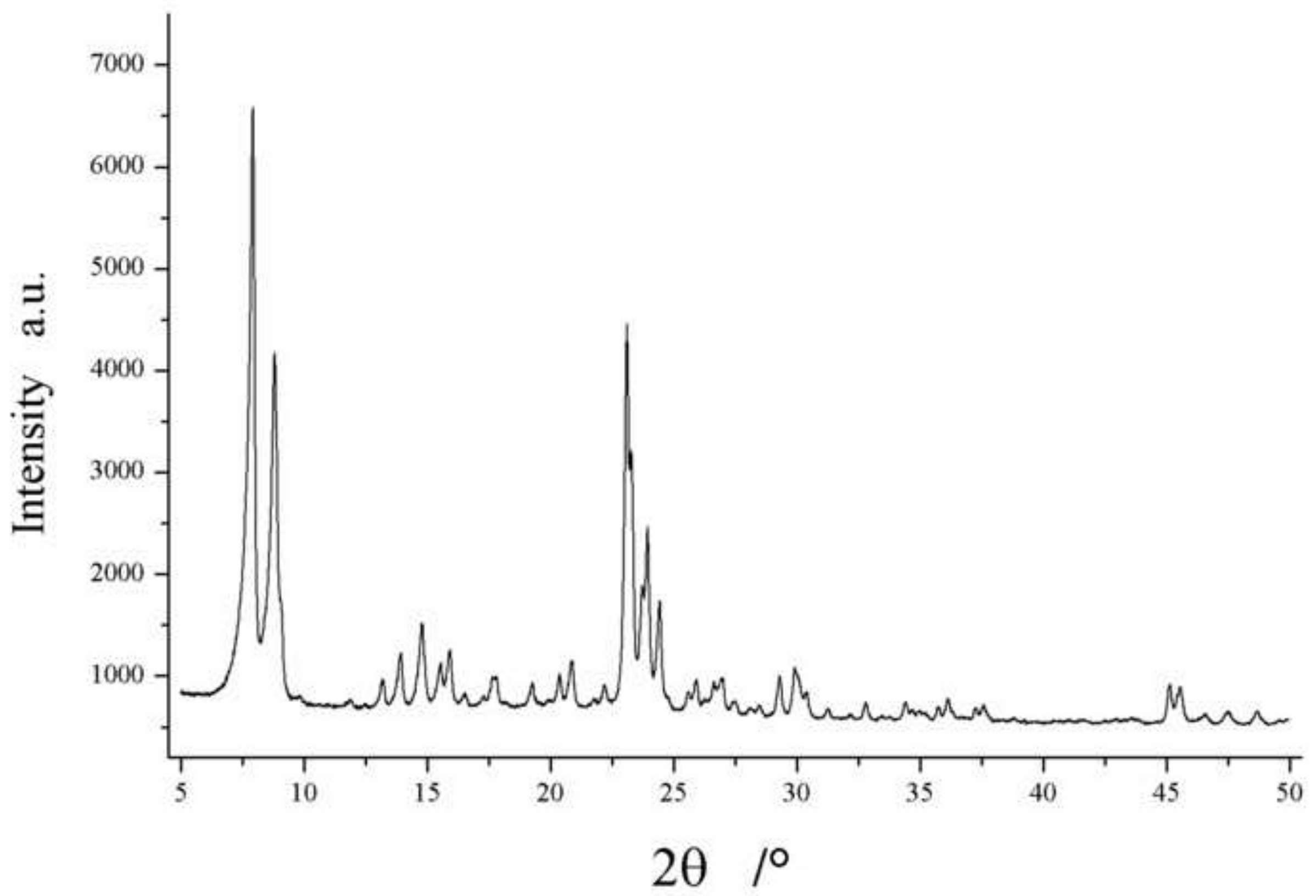

Page 48 of 49 


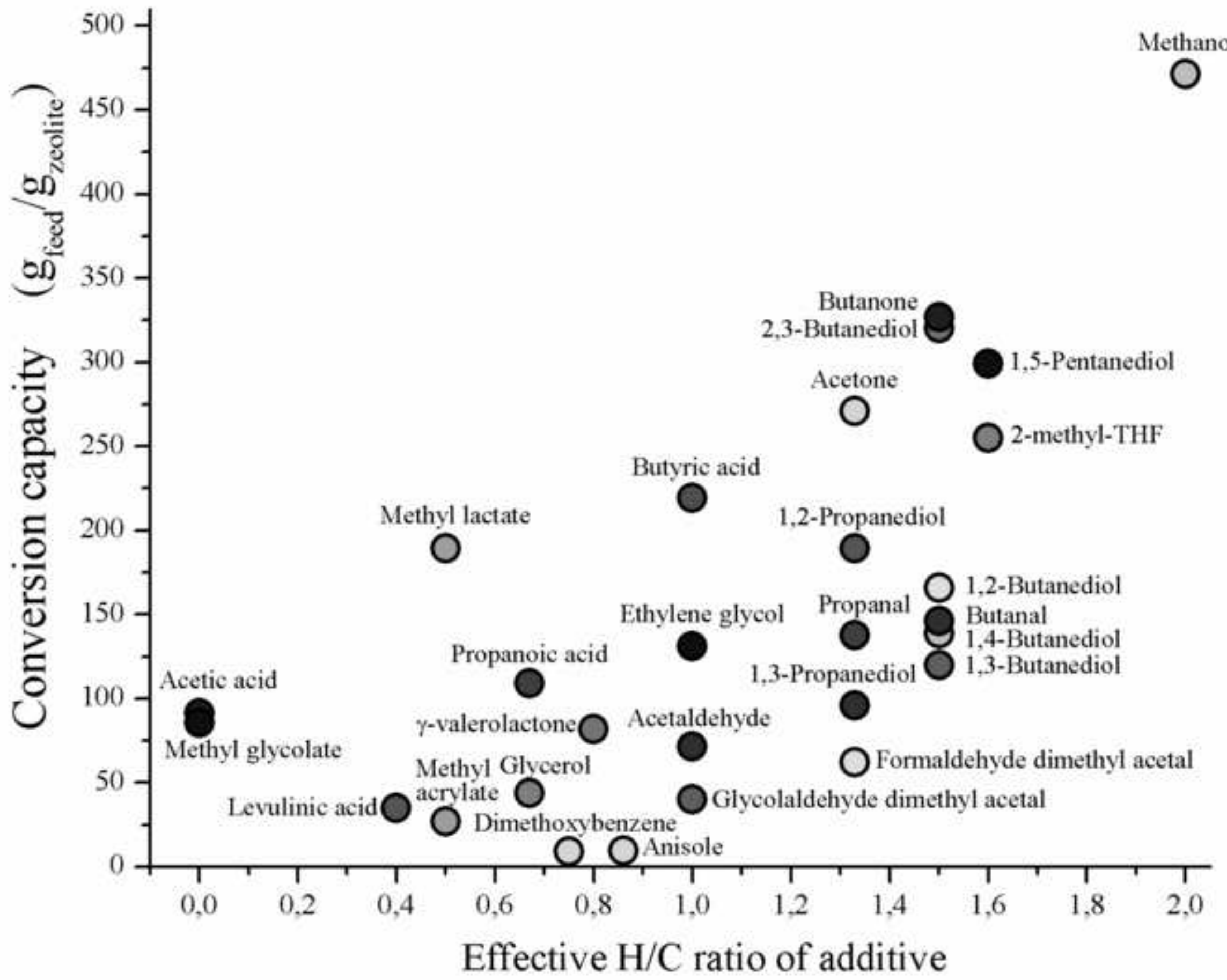

rage $4 y$ or $4 y$ 